Article

\title{
The Arts and New Materialism: A Call to Stewardship through Mercy, Grace, and Hope
}

\author{
Nicholas Leonard \\ Art and Design Education, Northern Illinois University, DeKalb, IL 60115, USA; \\ NicholasGLeonard@Protonmail.com
}

Received: 24 June 2020; Accepted: 13 August 2020; Published: 17 August 2020

\begin{abstract}
During highly polarized times, issues are quickly addressed in ways that emphasize divisions. To support the healing of our polarized culture through art, new materialist theory as presented by Karen Barad and Rosi Braidotti will be entangled with art and artmaking according to Dennis Atkinson and Makoto Fujimura to argue for art as an act of environmental and cultural stewardship, creating new possibilities and differences in the virtual that are merciful, graceful, and hopeful. To form this argument, first a summary of new materialism and ethics through Agential Realism and Affirmative Ethics is addressed. Next, a cartography including scientific and theological perspectives is presented for a diffractive reading regarding the concepts of mercy, grace, and hope to develop a new materialist understanding through a philosophy of immanence to counter the circular perpetuation of violence. These concepts are then individually addressed through the proposed new materialist framework to further break from material-discursive dualistic thought. This approach is then explored through various artworks to investigate the co-constructing material-discursive nature of art to create new relations and possibilities in the world. Finally, an in-depth study of the artworks Becoming Us by Megan Constance Altieri and Teeter-Totter Wall by Ronald Rael are addressed to detail how a new materialist approach to art that focuses on the concepts of mercy, grace, and hope can position art as an act of stewardship.
\end{abstract}

Keywords: art; new materialism; entanglement; stewardship; mercy; grace; hope; ethics; social justice

\section{Introduction}

We are living in highly divisive times where political, religious, and environmental conversations are quickly polarized (Pew Research Center 2020; Schaeffer 2020). Furthermore, the police murder of George Floyd in Minneapolis, Minnesota, has created international protests calling for social and racial justice (Hagemann 2020), highlighting injustices and divisions in attitudes between race and law enforcement (Desliver et al. 2020). While change is certainty needed, current polarization through binary thinking can create barriers between one individual and the other, hindering relationship building toward a better future (Butler 2020). This issue is an ethical concern since it addresses the principles of how people behave when interacting with others.

The intention of this article is to address how the arts can act as a cultural and environmental steward by approaching the ethical concepts of mercy, grace, and hope within a new materialist framework (Barad 2007; Braidotti 2019). The argument presented here is not to challenge one group or identify a middle ground in current cultural divisions such as conservative-liberal, theological-secular, or republican-democrat. Rather, the argument presented challenges individuals to approach artworks in a way that slows the conditioned urge to apply reflective and transcendent binary thought which enables these divisions to be constructed in the first place. By engaging artworks through a new materialist framework of immanence, the unspeakable tacit knowledge (Polanyi 1967) that emerges through interactions with matter is addressed to reposition cultural issues and questions towards what 
differences are made in our shared becoming. Since the focus of this article is to propose how art can heal cultural divisions by making differences in the world, the differences made need to counter the circular perpetuation of hate, anger, and violence (Butler 2020); thus merciful, graceful, and hopeful differences are needed. These terms will be diffractively read through their reflective secular and theological understandings in order to develop a new materialist understanding of what differences mercy, grace, and hope create within a philosophy of immanence. Through this approach, various worldviews can engage with artwork in a way to bring about new understandings which supports the healing our highly polarized culture.

While the selected artworks could be analyzed from a modernist understanding in an attempt to understand the artists' intent, or through a critical postmodernist lens for socially constructed meaning, the discussions presented here instead explore engagements with art through new materialist theory. Here, new materialist theory is crucial for moving beyond modern and postmodern binaries (Tuin and Dolphijn 2012) to explore the co-constituting material-discursive nature of the arts. To explore how art can promote cultural care across economic, environmental, racial, social, and political issues, artworks from around the world were selected and explored for how merciful, graceful, and hopeful differences can emerge. By selecting a variety of artworks that differ in material, scale, and location, a new materialist approach to experiencing artworks should be seen as an encompassing method that is not limited to a specific artwork genre.

To construct this argument, first a brief summary of new materialism theory is addressed in the works of Karen Barad (2007) and Rosi Braidotti (2019). Second, new materialist ethics is discussed through Barad's (2007) Agential Realism and Braidotti's (2019) Affirmative Ethics. Third, a cartographic discussion of ethics within the sciences and theology is presented to diffractively read through the concepts of mercy, grace, and hope, replacing dualistic thought with immanent thought (Tuin and Dolphijn 2012). Fourth, the proposed new materialist understanding of mercy, grace, and hope is explored in detail by providing artworks that exemplify these individual concepts by focusing on the worlds becoming rather than reflecting on prior constructs and relations. Finally, the arts are proposed as a conduit for stewardship by engaging the new materialist ethics of mercy and grace. In this final section, Becoming Us by Megan Constance Altieri and the Teeter-Totter Wall by Ronald Rael and supporting artists are discussed to clarify how artworks can simultaneously exemplify mercy, grace, and hope for cultural and environmental stewardship.

\section{Posthumanism and New Materialism}

Posthuman theory is an overarching term for theory that breaks from previous anthropocentric perspectives. Here, human aims and goals are decentered, allowing for other interpretations regarding the ontology, epistemology, and ethics of matter. One of the seminal researchers in this area who focused on postmodern subjectivity and feminist theory was Donna Haraway (1994, 2006, 2013, 2016). Haraway presented a critical and material-influenced view of gender and identity through exploring humanity and various technologies. Another seminal author, Hayles $(2008,2017)$, also focused on the significance of material and the body through a feminist lens. Together, their works can be referenced as posthuman publications, whereas New Materialism is a specific domain within posthumanism that gives special attention to matter by avoiding binary understandings such as mind-body and human-nonhuman. It is also important to note that posthuman and new materialist concepts are not new, as indigenous epistemologies and cosmologies offer ways of thinking that break from the human and nonhuman distinction (Nakata 2007).

Karen Barad (2007), and Rosi Braidotti (2019) are two current prominent new materialist theorists. Dolphijn and Tuin state that "Barad and Braidotti work towards a new materialism that is immediately ontological, epistemological, and ethical" (Tuin and Dolphijn 2012, p. 16). Their work is ontologically, epistemologically, and ethically focused since they emphasize the dynamic relationships of matter to focus on what new relationships form. According to Barad (2007), matter "does not refer to an inherent, fixed property of abstract, independently existing objects" (p. 151). Instead, matter is the collection of 
atoms that, only through their relations to other atoms, temporarily develop qualities as entities until a new relation is made. For example, the metal and wood that can constitute a hammer only becomes a hammer through its relation to other material. This means that new materialist understanding challenges how we identify subjects in existence since they are recognized as always in a process of becoming something else as the world and relations change (Barad 2007). This is also a challenge to understanding since we cannot operate under the assumptions of isolated individual subjects with predefined traits nor can we assume where the boundaries are of a subject being observed.

Consequently, our thoughts must address the complex relations in a moment and address what possibilities are opened and closed as matter relates to other matter (Barad 2007; Braidotti 2019). Furthermore, since all matter is connected through relations to other matter, which are either supporting and suppressing new potentialities, every action is an ethical action affecting and being affected by other matter. To appropriately reconceptualize the world through this new materialist understanding, dualistic thinking that imposes binary understandings must be replaced with immanent thought to recognize how entities are emerging and how these changes influence new immanent possibilities for future becomings. In order to begin approaching how new materialist theory as proposed by Barad (2007) and Braidotti (2019) manages to break away from dualistic thought through focusing on immanence, terms such as entanglements, becoming, and material immanence must be addressed. This transition to a new materialist framework is significant since it is the confrontational dualistic thinking being perpetuated in America politics (Pew Research Center 2020; Schaeffer 2020) that has incited cultural division.

\subsection{Entanglements}

Barad (2007) uses quantum physics to argue that matter is not ontologically, epistemologically, or ethically separate. This is accomplished through the concept of wave-particle duality. Here, light can be measured in multiple ways. When measured one way, light will act like a particle. When measured another way, light will act like a wave. This seems contradictory since particles are physical matter that cannot occupy the same space, while waves can overlap, building on each other, creating a superposition. Barad addresses this phenomenon by stating that the apparatus used to measure light forms a relationship with the light, causing certain traits to emerge from that moment.

Consequently, this means that matter does not exist with per-definable traits that can be represented. Barad (2007) refers to this complex relationship of matter to other matter as entanglements by stating that:

In an entanglement understanding, there are no separate predefined entities. Instead all matter exists, and it is through its relationships with other matter that boundaries and borders of entities can be defined for a moment. Interactions convey a sense of internal change of separate entities while intra-actions emphasize the co-constituting nature between matter in entanglements.

All matter is embodied and embedded in other matter in an entanglement. Furthermore, Barad (2007) replaced the term "interaction" with "intra-action" to represent the relations that form between matter rather than the relation of two subjects' traits converging. This means that matter is co-constituting and the world is dynamic, in the constant process of intra-activity and materialization (Barad 2007).

Since matter does not have any characteristics or qualities until a temporary relation is formed in an entanglement, agency is not located within matter. Barad makes this point vividly clear when she states that "agency is not something that humans and even nonhumans have to varying degrees" (p. 172). Just as Barad uses the term intra-action to emphasize that the action is located between matter through their relations, she also developed the term "agental cut" (p. 175) to locate agency between matter. Since matter is consistently forming new relations with other matter, a temporary relation becomes a "resolution for the ontological indeterminacy" (p. 175) by creating a material condition within a phenomena that provides a casual structure for the possibility of objectivity. Referring back to the research of wave-particle duality, the temporary relation formed between the material of the 
apparatus and material of light allowed to create a certain relation. This relation is an agential cut, creating a casual structure allowing certain qualities to emerge for the apparatus and the light.

\subsection{Becoming}

Since all matter is consistently embodied and embedded within other matter through intra-actions, it is never static. Consequently, it is more appropriate to state that all matter is in the process of becoming rather than per-existing. In this new materialist understanding, matter does not refer to a fixed substance; instead matter is substance in its intra-active becoming. Thus, becoming can be thought of as matters' continuous stabilizing and destabilizing process of iterative intra-activity (Barad 2007).

In recognizing that all matter is in the process of becoming, representationalist attempts to define matter lose validity due to perpetual materialization. Since objects cannot be identified as per-existing due to entanglements, they must be replaced with the understanding that objects emerge through a specific practice (Barad 2007). Furthermore, due to matter's iterative reconfigurations through each entangled intra-action, it is impossible to differentiate "between creation and renewal, beginning and returning, continuity and discontinuity, here and there, past and future" (Barad 2007, p. ix). This means that the history of matter cannot be understood in traditional past and future paradigms. Instead attention must be given to matter's intra-actions, which affect what becomes possible and what possibilities are denied (Barad 2007).

\subsection{Material Immanence}

Since matter's intra-actions re-configure space and time through one another, obscuring the traditional concepts of past and future, a new focus must be given to replace the traditional linear understanding of matter through time. Addressing this issue, Braidotti (2019) created the term 'materialist immanence' to describe "the immanent, and yet fluid, re-grounding of ourselves in the messy contradictions of the present" (p. 38). Here, Braidotti acknowledges that all human and nonhuman entities are transversal subjects in the process of becoming, bound to the self-ordering intra-actions of matter.

Braidotti (2019) builds on the concepts of the virtual, actual, and plane of immanence from the work of Deleuze and Guattari (Deleuze and Guattari [1980] 2005) to construct material immanence. According to Deleuze and Guattari, the virtual is a potentiality that can become fulfilled in the actual, which can be thought of as the present. Furthermore, the plane of immanence is a formless self-organizing process of the virtual to which matter is intrinsically connected. Since the plane of immanence is a virtual entanglement in the process of becoming, what interactions occur in the present influence the potentialities in the virtual for what is both possible and/or denied.

In identifying material immanence, Braidotti (2019) redirects attention away from the self to focus on the active becoming of the virtual. Similar to Barad (2007), the past and future do not ascribe to a traditional linear understanding. According to Braidotti

"the past is not a frozen block of half-accomplished deeds, but a heterogenous mass of future pasts awaiting historical actualization. And likewise, the future is the on-going unfolding of an unrealized virtual past". (Braidotti 2019, p. 65)

Consequently, posthuman thinking, according to Braidotti (2019), is the creation of concepts to assist with the complexities of the present with a focus on actualizing the virtual. Since our thinking and actions influence matter's becoming in the virtual, all our thoughts and actions need ethical considerations since "we-are-all-in-this-together-but-we-are-not-one-and-the-same" (p. 157).

\subsection{Diffraction and Immanence}

The new materialist framework developed by Barad (2007) and Braidotti (2019) is unique in how it addresses ontology, epistemology, and ethics (Tuin and Dolphijn 2012). The foundational approach 
to this new materialist framework involves breaking away from dualistic thought by developing a "new conceptualization of difference" (p. 115). ${ }^{1}$ Previous dualistic thinking was a pillar of modern and postmodern thought by imposing assumptions that there are always two categorically present entities or understandings such as mind-body and material-discursive. Tuin and Dolphijn (2012) summarize this understanding stating that:

Whereas a modernist scientific materialism allows for one, true representation of matter, and a postmodernist cultural constructivism allows for a plethora of equally true representations, it is the shared representationalism that is questioned and shifted by new materialism. (p. 107)

Breaking away from representationalism's attempt to define and describe per-existing entities, new materialism introduces "a philosophy of difference or immanence by working through or 'traversing' the dualisms that from the backbone of modernist thought" (Tuin and Dolphijn 2012, p. 86). Since matter is entangled and continuously becoming (Barad 2007), attempting to use reflective accounting for entities is no longer a valid practice. This is because imposing qualities on matter, which is always becoming, chooses to ignore temporary qualities being identified through agential cuts and instead applies transcendental concepts. Thus, a philosophy of difference (Barad 2007) or immanence (Atkinson 2017; Braidotti 2019) does not apply transcendental concepts by focusing on how relational differences get made and how these relations influence future possibilities.

A philosophy focused of difference and immanence is significant in the proposed new materialist framework for addressing art since both philosophies avoid dualistic thinking, which has recently caused cultural concern (Pew Research Center 2020; Schaeffer 2020). To avoid dualistic thinking, Barad (2007) proposes a "diffractive methodology" (p. 93) to investigate the boundary-making processes that allow for the production of objects and subjects. According to Barad, diffraction "involves reading insights through one another in ways that help illuminate differences as they emerge, how different differences get made, what gets excluded, and how those exclusions matter" (p. 30). This diffractive process explores the influence of relational differences that aligns with a philosophy of immanence (Atkinson 2017; Braidotti 2019). Immanent thought is forward thinking to what is becoming by addressing the potentialities consistently reorganizing in the virtual, in reaction to what is presently being actualized in the present. To this point Atkinson (2017) notes that:

It is crucial to acknowledge that the process of actualization does not produce a new 'thing' but a new relation, a disobedient relation in terms of former relations and a difference of potential. (p. 199)

Since a new materialist framework investigates the boundary-making processes within a relational ontology to explore how these relations come to matter through immanent thought, there are no transcendental concepts or dualistic thinking. This is significant when arguing for cultural stewardship through the arts since there is no longer a material-discursive binary separating meaning and matter. Barad (2007) explains that:

Discursive practices and material phenomenon do not stand in a relationship of externality to each other; rather, the material and the discursive are mutually implicated in the dynamics of intra-activity. (p. 119)

As a result, rather than addressing reflective binary thought in artworks, such as a political cartoon, new materialism investigates how engaging with the matter of an artwork can produce new relational differences. The new relation to matter forms an agential cut between the observer and the artwork which has rippling effects in the immanent virtual. This is similar to how Atkinson (2017) argues for

1 The seminal work by Tuin and Dolphijn in their open access publication New Materialism: Interviews $\mathcal{E}$ Cartographies provides significant detail regarding how Barad's and Braidotti's work breaks away from dualistic thought. 
a pedagogy of immanence when frequently referencing artworks and artmaking. Furthermore, this approach to art aligns with art educators Siegesmund and Freedman (2018), who argue that engaging with art and materials is a focus on tacit knowledge (Polanyi 1967) which is an insight that cannot be immediately articulated. This tacit knowledge cannot be articulated since a new relation is formed that defies previous relations stating:

Words and numbers - those things that are known — can diminish the tacit, for the tacit is what lies beyond our grasp. The image is not a recording. It is not a depicting. It is a reaching. It is a reaching for a potentiality—a tacit dimension. (Siegesmund and Freedman 2018, p. 36)

Thus, by engaging with art within a new materialist framework, art is not a symbolic binary statement but a provocation to change the becoming of the world. Since all matter is entangled, how the world is changing becomes an ethical matter.

\section{New Materialism and Ethics}

Barad (2007) and Braidotti (2019) both conclude their publications by discussing the ethical implications of a new materialist understanding. This is a transition from describing the world to describing how things ought to be in the world through a new materialist perspective. While they both recognize the entangled co-constructing nature of matter, their ethical compasses point in the same direction from different locations, specifically agential realism and material immanence. Through a diffractive reading of these two texts, differences can be identified along with what is excluded and how those exclusions come to matter in reforming the virtual.

\subsection{Barad and Agential Realism}

Barad (2007, p. xi) starts her argument by stating that the driving force behind her work is the yearning for justice greater than any individual, which is our connections and responsibilities to others, called entanglements. Here, Barad is calling for an ethical focus in which a person's actions should be recognized as always influencing others, since a byproduct of entanglement is that "it is not possible to extricate oneself from ethical concerns" (p. 37). To form this argument, she uses quantum physics to argue that all matter is changing and there are no predefined traits.

Since Barad's (2007) argument focuses on experiments in quantum physics, the implications are generally directed toward scientific practice that are then extrapolated to ethical concerns. The logical threads woven through the text emerge in her final chapter on the ethics of mattering. According to Barad, responsibility is not just present for human to human encounters since a subject's boundaries, including humans, are constantly in flux through intra-active becomings (p. 392). Furthermore, these intra-actions influence what is real and what is possible, meaning there is no singular cause of individual agent of change and that all matter is important in shaping the virtual.

The driving force of this argument is recognizing how dynamic and significant matter is in everything due to entanglements and matter continuously becoming. While this argument for an Agential Realist account is started with the example of a scientist's measurement apparatus being responsible for co-creating the subject (Barad 2007, p. 37), this theory is expanded to address other entanglements. Thus, when these Agential Realist concepts are placed into the ethical issues of daily lived experiences for the layperson, the concerns focus on recognition of human-nonhuman relations that together influence what is possible. Barad summarizes this point in her closing sentence stating:

Meeting the moment, being alive to the possibilities of becoming, is an ethical call, an invitation that is written into the very matter of all being and becoming. We need to meet the universe halfway, to take responsibility for the role that we play in the world's differential becoming. (p. 396) 


\subsection{Braidotti and Affirmative Ethics}

Over a decade later, Braidotti (2019) continued developing new materialist theory with a particular focus on ethics. In her publication, Posthuman Knowledge, Braidotti asks "in times of war, conflict and social upheavals, what is the suitable way to pursue social justice, critical feminist thought, radical ecologies, anti-racism, equitable sustainability and education for peace" (p. 122). Using the new materialist concepts of matter's entanglement and becoming, Bradiotti speaks to an ethics of addressing the present for influencing the virtual through Affirmative Ethics.

According to Braidotti (2019), Affirmative Ethics can be described "as a collective practice of constructing social horizons of hope, in response to the flagrant injustices, the perpetuation of old hierarchies and new forms of domination" (p. 156). Through affirmative ethics, Braidotti calls for a critical engagement with the present for an entangled understanding of the actual and what virtual possibilities are made possible. Consequently, Braidotti shapes her argument to directly address social justice issues through material immanence, introducing the term "We-Are-All-In-This-Together-But-We-Are-Not-One-And-The-Same" (p. 52). This shares some similarities with the ethics outlined by Barad where "subjectivity is not a matter of individuality but a relation of responsibility to the other" (p. 391).

Unlike Barad, Braidotti (2019) details how our intrinsic connections to others as well as the conditions we are attempting to influence produce new understanding of good and evil and ways to process pain and vulnerability. According to Braidotti, "the normative distinction between good and evil is replaced with that between affirmation and negation, or positive and negative affects" (p. 166). By adjusting ethics from moral protocols, norms, and values, ethics according to Braidotti focuses on the conditions of affirmative becoming. This is argued as a more conceptual and pragmatic understanding of ethics with a focus on a material immanence and processing negativity in a way to transform it for a better shared becoming.

It is clear in both cases that matters entanglement, becoming, and influence of the possibilities that emerge in the virtual guide Barad's (2007) and Braidotti's (2019) worldviews. Furthermore, our entanglement with all matter presents an argument for how things ought to be by providing a greater-than-self ethical consideration of how actions influence the virtual for all matter. It is also crucial at this point to mention that "it should be understood that Indigenous thinkers and scholars developed ideas about non-human agency thousands of years earlier than contemporary philosophers of science" (Rosiek et al. 2020, p. 2). Rosiek, Snyder, and Pratt (Rosiek et al. 2020) have also noted that multiple Indigenous scholars (De Line 2016; Higgins 2017; le Grange 2018; Martin 2017; Todd 2016; Tuck and McKenzie 2015; Watts 2013) have published comparisons between Indigenous scholarship and recent posthuman scholarship. This is significant to the current discussion since Indigenous scholars have already been exploring the ethical and moral implications of nonhuman agency (Coulthard 2014; Coulthard and Simpson 2016; Deloria 1988, 1999a, 1999b; Martin 2017; Simpson 2017; Todd 2014; Watts 2013) rather than trying to justify nonhuman agency like current posthuman research. In order to begin exploring how ethics and morality has been addressed in various worldviews, a brief cartography will be provided.

\section{A Brief Cartography of Ethics and Morality in Science and Theology}

Since all matter is dynamically in the process of becoming, a performative and nonlinear account of how matter emerges into the present can provide a critical lens for engaging with entanglements. Barad (2007), Braidotti (2019), and Cameron (2018) support the use of cartographic accounts for mapping out and understanding matter's becoming in complex entanglements. Barad states that "the responsible practice of science requires a rich genealogical accounting of the entangled apparatuses or practices that produce particular phenomena" (p. 390). As a result, there is a responsibility to analyze and map out how the concepts of mercy, grace, and hope have emerged in this paper through both scientific and theological lenses. These concepts were intentionally selected to address the confrontational dualistic thinking perpetuated by leaders that becomes categorized politically and religiously, such as 
evangelical-liberal or republican-democrat (Pew Research Center 2020; Schaeffer 2020). This is not an argument to engage in linguistic theft or combine new materialist theory with Christian theology, which would further perpetuate representational thought. Rather, by diffractively exploring the dualistic and representationalist understanding of these concepts, a new materialist understanding can develop that resists binary understandings by directing attention to how differences of ethics as mercy, grace, and hope can influence the worlds becoming. Furthermore, the ethical concepts of mercy, grace, and hope were selected with the intention of providing generally agreeable traits that could be approached from a multitude of worldviews to then progress into an immanent new materialist understanding.

By describing what the world is through a new materialist perspective, Barad (2007) and Braidotti (2019) provide a perspective for clarifying and explaining how things occur. At the end of their writing, they provide suggestions as to how one should act from a new materialist perspective, recognizing matter as embodied and embedded in other matter through entanglements and material immanence. The final chapters of these writings jump from describing what the world is to what ought to occur in the world. This is/ought distinction has been notably detailed by Hume (2003), who stated that to convert a set of "is" premises into "ought" statements is invalid and a logical fallacy. In loose terms, this is because science tells us what is (descriptive), whereas moral and ethical behavior describes what ought to be (prescriptive). This is a notable dilemma, as ethics and morals have shared influence on how we think and act and a foundation must be laid to formulate a basis for ethical and moral actions. Furthermore, clarification must be made as to how an ethics of mercy, grace, and hope have emerged in both scientific and theological understandings. By presenting a brief cartography on scientific and theological studies relating to mercy, grace, and hope, it is my intention to show how these two realms of study have more in common, while maintaining their separate discipline boundaries, on this theme than one may previously acknowledge.

The Moral Landscape by Sam Harris (2011) presents an argument that science can provide an objective understanding of morality and directly responds to the is/ought distinction by Hume (2003). This intention is clearly stated in the title of Harris's (2020) TED talk "Science can answer moral questions" in which he continues his discussion on the moral landscape. In the moral landscape, Harris (2011) creates multiple peaks and valleys of varying heights and depths representing human well-being. This visual presents ranges of well-being that are contextual and situationally dependent that are argued to be supported with objective scientific fact. Using emerging discoveries in areas such as neuroscience and social science, Harris claims that human values can be reduced to facts and studied, allowing objective claims to be made in regard to well-being.

Challenging the scientific approach to morality, publications such as David Hunter and Paul Nedelsky's (Hunter and Nedelisky 2018) Science and the Good: The Tragic Quest for the Foundations of Morality directly respond to claims that science can explain morality. Their argument documents how science over the past 400 years has attempted and failed to explain morality through investigation and new technologies. This argument includes Hume's (2003) is/ought distinction along with specifying that the term morality may take on various understandings in the sciences where:

In place of moral goddess, they substitute the merely useful, which is something science can discover. Despite using the language of morality, they embrace a view that, in its net effect, amounts to moral nihilism. (Hunter and Nedelisky 2018, p. xv)

While this argument has received materialist critique (Wiebe 2019), comparisons can be made regarding their line of thought that require faith in a particular worldview. Faith as commented on by physicist Paul Davies during his 1995 Templeton Prize address stated that "science can proceed only if the scientist adopts an essentially theological worldview" (Davies 2020). Put another way, a scientist must also have a level of belief and faith that the world operates in a logical manner that can be observed and measured. Thus, rather than addressing morality in a binary way, between science and religion, arguments can and have been made to see what new insights come from a sincere cross-disciplinary discussion. 
By placing science and religion's quest for understanding regarding ethics and morality against each other, an unnecessarily dualism is created, implying that you can only be of a scientific mind or religious conviction. Many philosophers and other academics have addressed this and parallel issues in the Gifford Lectures, an annual series on the theme of natural theology. Over the past century, these lectures have advanced discussions of philosophy and theology. The participating lecturers have included John Dewey, who has held significant influence in American in art education theory. In 1929, Dewey presented The Quest for Certainty at the Gifford Lectures and argued that humanity prefers a firm understanding and has developed various intellectual methods and regulations to control for variables to produce an enduring truth or understanding. Here, he outlines how humanity has transitioned its search for understanding from religious to rational and then to philosophical endeavors. He concluded that philosophers have been attempting to adjust theory to meet scientific discoveries in vain and must adopt a more scientific method using hypotheses to develop better futures for humanity.

A recent Gifford lecture by Judith Butler (University of Glasgow 2018) addressed the ethics of non-violence through critical and social theories (Butler 2020). Here, she critically investigates the socially constructed and dependent nature of all people. She continues this critical line of thought to nonhumans stating "the relations that bind and define extend beyond the dyadic human encounter, which is why nonviolence pertains not only to human relations, but to all living and inter-constitutive relations" (p. 9). This greater-than-self postmodern critical theory still remains within dualistic thought by addressing reflective divisions such as violence-nonviolence and self-other. This line of thought critiques the agency and power of individuals and groups which are socially constructed. While exploring ethics of non-violence is a worthy endeavor, the critical and social framework argues for an "altered state of perception, another imaginary, that would disorient us from the givens of the political present" (p. 64). Through the introduction of a new materialist framework, the new perspective through a philosophy of immanence allows for an argument for art as a cultural and environmental steward. New materialism, then, is a framework that is not only greater-than-self, but a greater-than-humanity understanding for addressing what we are becoming. This approach then can be understood as a response to Butler's (2020) call that the human and nonhuman relations raises "all kinds of questions about stewardship that deserve full attention from scholars and intellectuals across all fields" (p. 199).

In a similar attempt to promote better futures and becomings are the works of earlier Gifford Lecturers John Polkinghorne $(2005,2007,2010)$ (Polkinghorne and Levett 1994) and Wentzel Van Huyssteen (2006). These works provide more entangled understanding of emerging scientific and religious studies within a new materialist framework that can promote a mutual appreciation for stewardship through the arts with a focus on matter and ethics. As both a scientist and theologian, Polkinghorne (2010) has written and presented extensively on how studies in quantum physics and theology are both focused on a search for truth through a critical realist account. Similar to Dewey's (Dewey [1984] 2008) argument for a more scientific method to be used in philosophy made nearly a century earlier, Polkinghorne (2007) discussed how both scientific and religious endeavors in a critical realist account address moments of enforced radical revision-a period of unresolved confusion, new synthesis and understanding - and continued wrestling with unsolved problems. This is significant becoming of quantum scientific research and theology, as Barad's (2007) Agential Realism and Braidotti's (2019) Affirmative Ethics are both built on a scientific understanding of quantum mechanics. Thus, by placing the search for truth from scientific and theological domains as shared and parallel endeavors (Polkinghorne 2007), a complementary theoretical bridge can be formed to address how our interactions with matter can direct us to an ethical understanding for approaching topics of mercy, grace, and hope.

Furthermore, Wentzel Van Huyssteen (2006) advocate for increased interdisciplinary dialogue through the shared resource of human rationality. In his Gifford Lecture, Van Huyssteen argued for postfoundationalism in an attempt to highlight shared rational approaches while avoiding the 
objectivism of foundationalism and the relativism of nonfoundationalism. In this work, Van Huyssteen (p. 46) states:

A postfoundationalist approach should enable us to realize that there is also much that we share, and help us identify these shared resources of human rationality in different modes of knowledge as to reach beyond the boundaries of our traditional communities in cross-contextual, cross-disciplinary conversation.

In applying this postfoundationalist approach, Van Huyssteen (2006) addresses the concept of human uniqueness through rational arguments by referencing the art within the Cave of Gargas, entangling paleoanthropology and theology. While this transversal moment of discussion between disciplines is beneficial for sharing resources addressing parallel research, Van Huyssteen notes that there are "natural limitations" (p. 323) to these conversations. These points of separation reveal limits of cross-discipline transversal moments where "disciplinary lines of argument necessarily diverge again and move back to intra disciplinary contexts, carrying with them the rich interdisciplinary results of the multidisciplinary conversation" (p. 323).

Through these critical realism (Polkinghorne 2007) and postfoundationalist (Van Huyssteen 2006) approaches bridging scientific and theological study, many correlations to Csikszentmihalyi's (1996) work on creativity and discovery can be identified. In his seminal work, Csikszentmihalyi provides ample evidence through snowball sampling that "creativity generally involves crossing the boundaries of domains" (p. 9). In this social psychology understanding of creativity, different domains produce criteria to identify ideas of value. To have a creative discovery, novelty must be brought into a domain that also meets the established criteria for value. Csikszentmihalyi persuasively argues that when the content knowledge of domains overlap, opportunities for creative insights present themselves when applying the perspective of another domain. In this manner, the application of critical realist (Polkinghorne 2007) or postfoundationalist (Van Huyssteen 2006) approaches introduce opportunities for rigorous scientific and theological discussion of ethics and morals.

Furthermore, a diffractive reading of ethics and morality would be enriched by the longstanding works and knowledge from Indigenous studies. In Deloria's (1999b) discussion of Sioux tribal knowledge he addresses the moral implications this understanding, stating that:

In the moral universe all activities, events, and entities are related, and consequently it does not matter what kind of existence an entity enjoys, for the responsibility is always there for it to participate in the continuing creation of reality. (p. 47)

In order to avoid the colonization of Indigenous knowledge, it should be recognized that these concepts have developed over a long period of time and have rich and complex backgrounds that should not be removed from their context. For example, in order to address epistemological and ontological understandings, Watts (2013) provides glimpses of Anishnaabe and Haudenosaunee knowledge that "can sometimes take days to describe" (p. 21). While this section only provides a brief cartography there should be "sustained engagement with agent ontologies found in Indigenous studies literature and Indigenous traditions of thought" (Rosiek et al. 2020, p. 13) in continued research and inquiry.

By providing a brief cartography of scientific and theological discussions on morals and ethics, diffractive readings and cross-disciplinary discussion are encouraged to explore how differences are made and how these differences come to matter. This is a significant endeavor as the highly polarized times are actively working toward the division and denial of multiple perspectives. Recalling that a diffraction methodology is not a reflective approach but explores how differences emerge, this reading of scientific and theological accounts should be read thought for a new understanding (Tuin and Dolphijn 2012). This new understanding does not "pick a side," which would perpetuate a binary worldview, but rather presents a new perspective of present phenomena. Furthermore, in an attempt to help bring together a divided culture, this article seeks to address a cross-disciplinary discussion on ethics 
regarding the concepts of mercy, grace, and hope within a new materialist framework. Through the proposed interdisciplinary reasoning, new materialism creates an apparatus that helps articulate mercy, grace, and hope through matter, allowing conversations among scientific and theological worldview.

\section{Ethics and Stewardship for Better Becomings}

Presently, America is highly divided, with polarized groups representing divergent worldviews (Pew Research Center 2020; Schaeffer 2020). To engage in meaningful and respectful dialogue regarding ethical behavior, the concepts of mercy, grace, and hope are addressed from a new materialist perspective, presenting a theoretical bridge for scientific and theological worldviews to begin mending current cultural divisions by focusing on immanence and becoming. These concepts have intentionally been selected to support respectful and engaging moments between the highly divided groups in America, commonly referred to through binaries such as conservative-liberal, evangelical-secular, and republican-democrat. The selection of these terms should not promote linguistic theft as a theological foundation for mercy, grace, and hope in theology presents a natural limitation but does not discount the potential benefits of multidisciplinary discussion regarding ethical behavior (Van Huyssteen 2006). Furthermore, it should be recognized that the act itself of addressing language from multiple theoretical foundations that include new materialism presents natural limitations to the understanding of language and identity (de Freitas and Curinga 2015). In spite of these limitations, it is through these discussions that the concepts of mercy, grace, and hope can begin to temporarily align across domains, allowing for implications within the arts to be actualized.

\subsection{A Case for Mercy}

The concept of mercy can be described differently from both secular and theological foundations. Despite the different perspectives of the concept, an immanent understanding of difference between the two could be agreed upon. In this section, mercy is first briefly addressed from both secular and theological positions. Second, a proposal for understanding mercy within a new materialist framework is introduced. Finally, an example of mercy is provided to further clarify how mercy is actualized in a new materialist understanding.

According to the Merriam-Webster dictionary ${ }^{2}$ mercy can be understood as lenient or compassionate treatment, a blessing that is an act of divine favor or compassion, or compassionate treatment of those in distress. A trend of compassion can easily be identified within these three understandings, while the source or reason for compassion is not always clearly recognized. Here, the second description provides a theological approach with a divine source, while the third description details that compassion is applied to those in distress. When addressing mercy from a theological perspective, according to Baker's Evangelical Dictionary of Biblical Theology (Baker's Evangelical Dictionary of Biblical Theology 1897a), mercy is God's compassion for his creation to do for it what it cannot do for itself. Thus, by withholding the judgment and punishment humanity deserves, God's mercy alone provides salvation for his creation. In this understanding, it is clear that mercy is originating from God to his creation who rightly deserves judgment. Furthermore, since God has shown humanity mercy, we can show mercy to others.

In addressing mercy within a new materialist framework, a similar emphasis can be placed on compassion by withholding punishment that is rightly deserved. In a new materialist understanding that matter is in the continual process of becoming (Barad 2007), Braidotti (2019) has proposed Affirmative Ethics to rework negativity and pain in the pursuit and actualization of positive relations. Here, we can observe a similarity in showing compassion as Braidotti states that "rather than a lack of compassion, it [Affirmative Ethics] is instead an oversupply of it" (p. 168). This statement is then supported by arguing that a subject is in the continual process of embedded and embodied becoming

2 Merriam-Webster Dictionary, s.v. “Mercy". https://www.merriam-webster.com/dictionary/mercy (accessed on 28 May 2020). 
of which "we-are-all-in-this-together" (p. 168) and we are entangled with the subjects' transformation. This is a dramatic break from a binary understanding of individual/other and right/wrong punishment.

Within this proposed understanding of mercy in a new materialist framework, there needs to be a recognition that 'you' are equally entwined with the development and becoming of the 'other' and an act of compassion could be to withhold negativity and pain to actualize positive transformation. This act of compassion does not require the avoidance or denial of negativity and pain, but it does require the depersonalization of an event to "transform its negative charge" (Braidotti 2019, p. 167). To better explore a new materialist understanding of mercy, the artwork Perception by eL Seed is discussed.

The artist eL Seed is a French-Tunisian street artist who uses the style of Arabic calligraphy he calls "calligraffiti" (Heardman 2019) to "spread messages of peace, unity and to underline the commonalities of human existence" (Seed 2020). In his artmaking, eL Seed has traveled around the world spending extended periods of time engaging with communities to identify an appropriate quote for calligraffiti to summarize the community within which he is working. Rather than creating an artwork prior to arriving in a community, eL Seed shows compassion by slowing down to understand the complexities of a community's entanglement. To deeply engage with eL Seed's work for a better understanding of mercy, his project Perception (Figure 1), located in the Manshiyat Nasr neighborhood of Cairo, Egypt, is discussed.

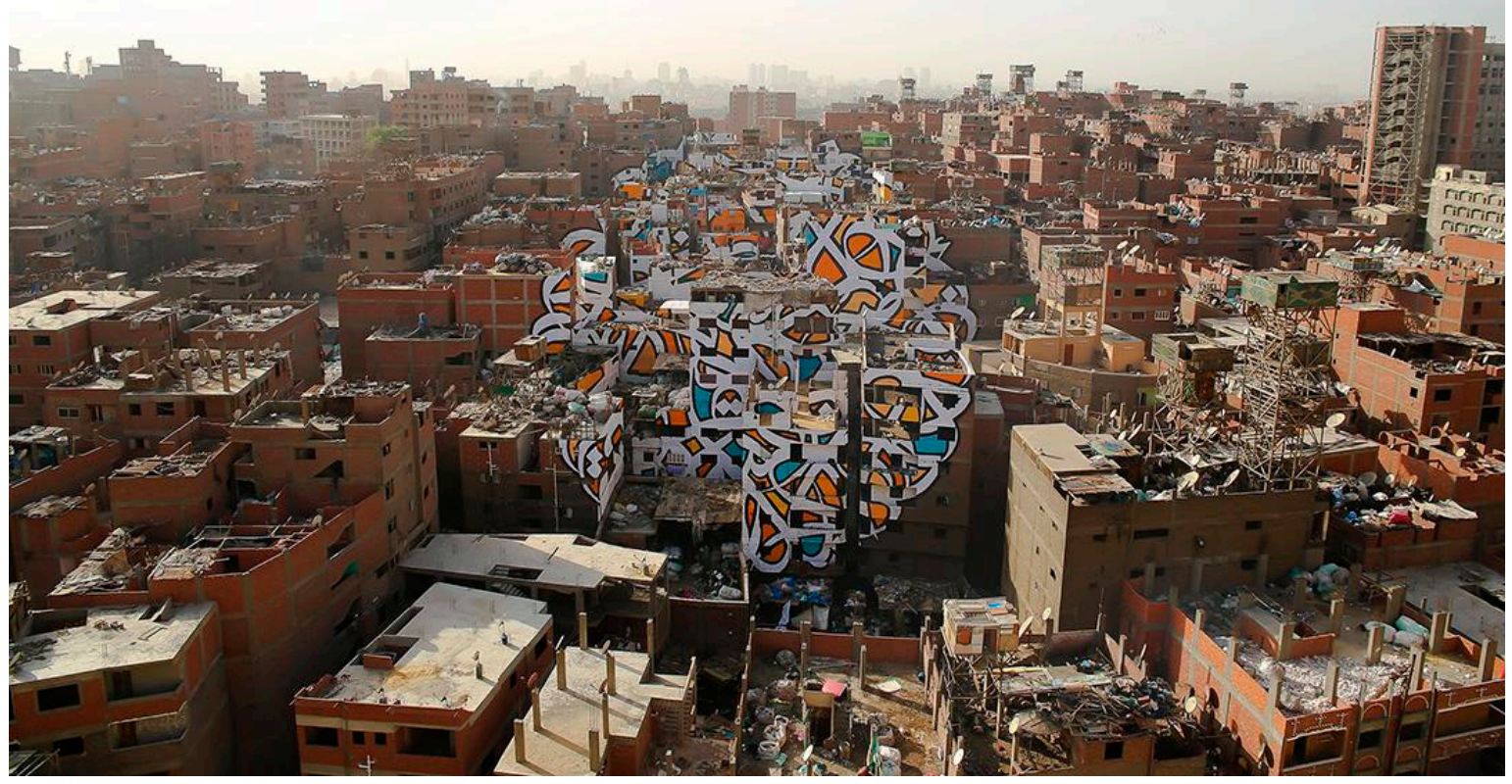

Figure 1. Photo of eL Seed's Perspective calligraffiti artwork in Cairo, Egypt (Photo by Ouahidb https://en.wikipedia.org/wiki/EL_Seed\#/media/File:Zaraeeb.jpg).

The Manshiyat Nasr neighborhood of Cairo is a deeply entangled community within the city of Cairo. Part of this entanglement includes collection of the city's trash, which has occurred for decades. Despite developing "the most efficient and highly profitable recycling system on a global level" (Seed 2020), Manshiyat Nasr is perceived as a marginalized and filthy slum where people are referred to as "Zabbaleen," meaning "people of the garbage." Rather than engaging in continuing this rhythm or pattern of identification, eL Seed can be understood as withholding negative judgment and instead act in compassion to engage in a complex entangled understanding to actualize a positive transformation. 
Using his calligraffiti art, eL Seed created an anamorphic artwork that covered nearly 50 buildings in the Manshiyat Nasr neighborhood. This giant piece of art is intended to be viewed from a certain point on the nearby Moqattam Mountain to read the full calligraffiti quotation from the 3rd century Coptic Bishop Saint Athanasius of Alexandria: "Anyone who wants to see the sunlight clearly needs to wipe his eye first" (Seed 2020). While this artwork has many symbolistic aspects that should not go unnoticed, a new materialist understanding is concerned with the intra-actions that emerge to create the artwork and the viewer and what differences are made as a result of that intra-action. The entanglement of the Moqattam Mountain, Manshiyat Nasr neighborhood, sunlight, and paint create an opportunity for a rupture from previous understandings (Atkinson 2017) in which the art encourages new social knowledge and empathy (Sherman and Morrissey 2017). Here the collection of buildings, paint, and viewing perspective specifically challenges previous flows of understanding where negative judgment was applied and, in doing so, applies mercy to the becoming of Manshiyat Nasr.

\subsection{A Case for Grace}

Grace also has similar, yet different, secular and theological understandings that can be entangled within a discussion on new materialist ethics for diffractive analysis. According to the Merriam-Webster Dictionary, ${ }^{3}$ grace can be the disposition to or an act or instance of kindness, courtesy, or clemency, a temporary exemption. Other more theological descriptions of grace are also provided, such as unmerited divine assistance to humans for their regeneration or sanctification, a virtue coming from God, or a disposition to or an act or instance of kindness, courtesy, or clemency, a temporary exemption. When addressing an understanding of grace according to Baker's Evangelical Dictionary of Biblical Theology (Baker's Evangelical Dictionary of Biblical Theology 1987b), grace is defined as the unmerited favor of God toward man. In this theological understanding, God provides his creation with that which we do not deserve. Once again there are strong parallels between both secular and theological definitions, specifically regarding unmerited favor or kindness. Unlike mercy where negativity is withheld when it is deserved, grace is providing kindness when it is not deserved.

Applying this concept of grace to a new materialist framework in which subjects are in the continual process of becoming, there is no prerequisite for transforming negativity for a shared positive becoming. In this understanding, grace is the application of kindness for the shared positive becoming. Put another way, in observing all matter as dynamically becoming, grace is the unmerited application of favor to actualize better becomings. It is important to acknowledge that the discussion of what qualifies as a "better becoming" presupposes various positive and negative stances that have natural limitations in secular and theological discussion. What a cross-discipline discussion of grace provides is a shared argument for a general increase in unmerited kindness towards matter since "We-Are-All-In-This-Together-But-We-Are-Not-One-And-The-Same" (Braidotti 2019, p. 52).

To further explore a new materialist understanding of grace through art, the Crochet Coral Reef (Figure 2) project by the Australian twin sisters Margaret Wertheim and Christine Wertheim, and their Los Angeles based Institute for Figuring (Wertheim 2020) is discussed. The Crochet Coral Reef is described as "an unlikely fusion of mathematics, marine biology, handicraft and collective art practice" and as "a beautiful impassioned response to dual calamities devastating marine life: climate change and plastic trash" (Wertheim 2020). In the Crochet Coral Reef, the artists use crocheting techniques to create coral reef installations as well as support communities around the world to create their own satellite reefs. Mathematics becomes entangled with the artwork through hyperbolic geometry crochet patterns discovered by Taimina (2018). This cross-disciplinary exploration, as explained in Margaret Wertheim's TED talk (Wertheim 2009), introduces not only beautiful and complex artworks but also an embodied form of knowledge. In this act of artmaking, adjustments to crocheting patterns can produce an infinite "woolly taxonomy of crochet organisms" (Wertheim 2009). 


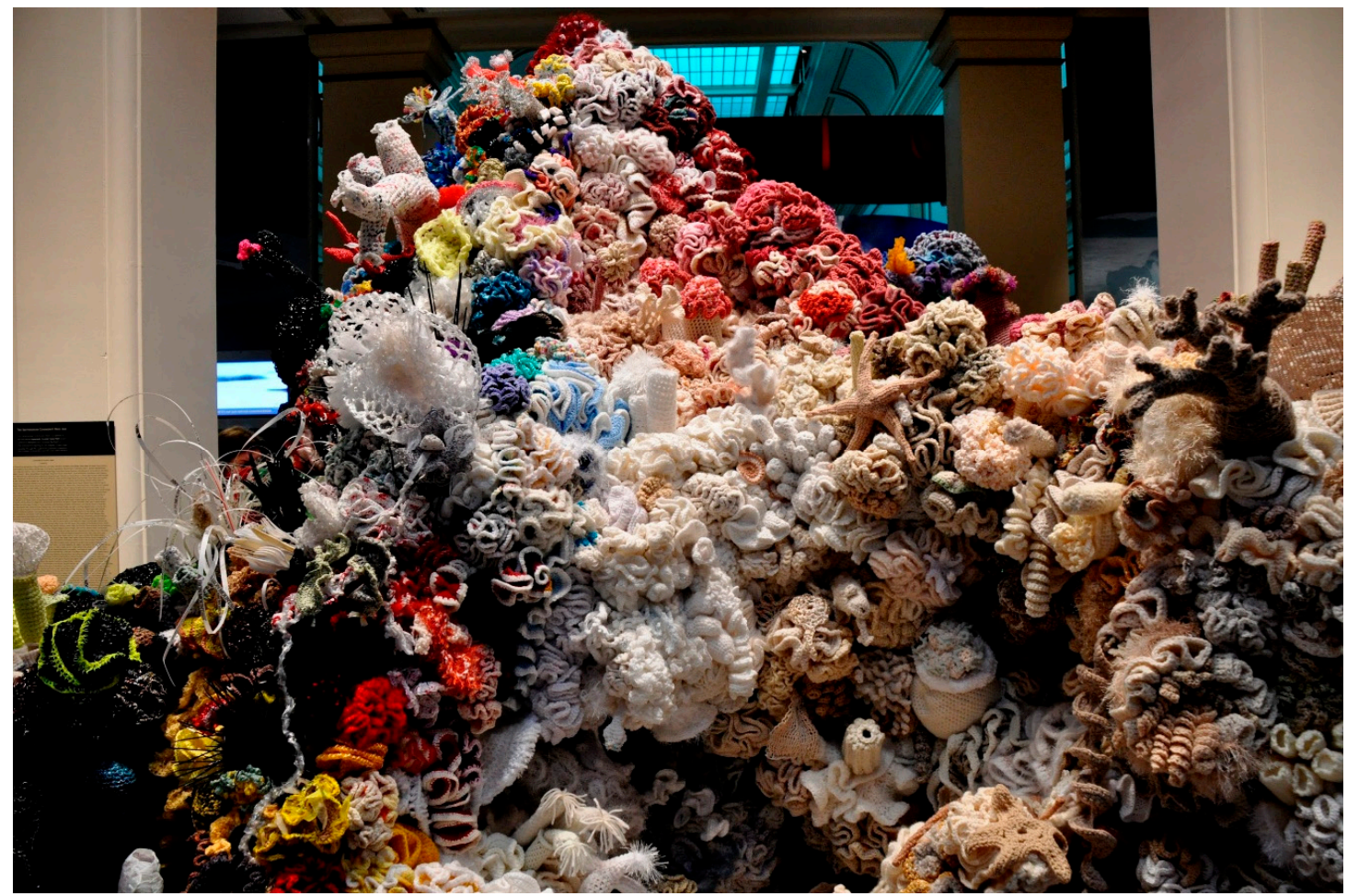

Figure 2. Hyperbolic Crochet Coral Reef exhibit at the Smithsonian's National Museum of Natural History in Washington, D.C., 2010 (Photo by Ted https://www.flickr.com/photos/frted/5115937870/).

The Crochet Coral Reef can be understood as an example of artistic grace from a new materialist perspective as the work engages with beauty for an unmerited application of kindness to transform negativity. The devastation to the Great Barrier Reef can be seen as a call to justice regarding the issues of climate change and pollution. ${ }^{4}$ Rather than reacting to this negativity with due judgment, unmerited kindness is shown by engaging people and materials around the world to the complex hyperbolic beauty displayed in coral reefs (Figures 3 and 4). In doing so, participating artists are entangled with material and concepts over the slow and meticulous process of crocheting. Here, as the artwork emerges in the process of becoming, new relations and differences are created for both the human and nonhuman subjects. While there are many potentialities in the virtual for reacting to the destruction of the Great Barrier Reef, the actualization of the Crochet Coral Reef is an unmerited transformation of negativity. The grace of this art project blesses communities with artworks entangling better becomings in the areas including, but not limited to, mathematics, climate change, and pollution.

4 Further investigations on posthuman and new materialist frameworks for addressing environmental issues would benefit from resources addressing terms including but not limited to the Anthropocene, Capitalocene, and Chthulucene. 


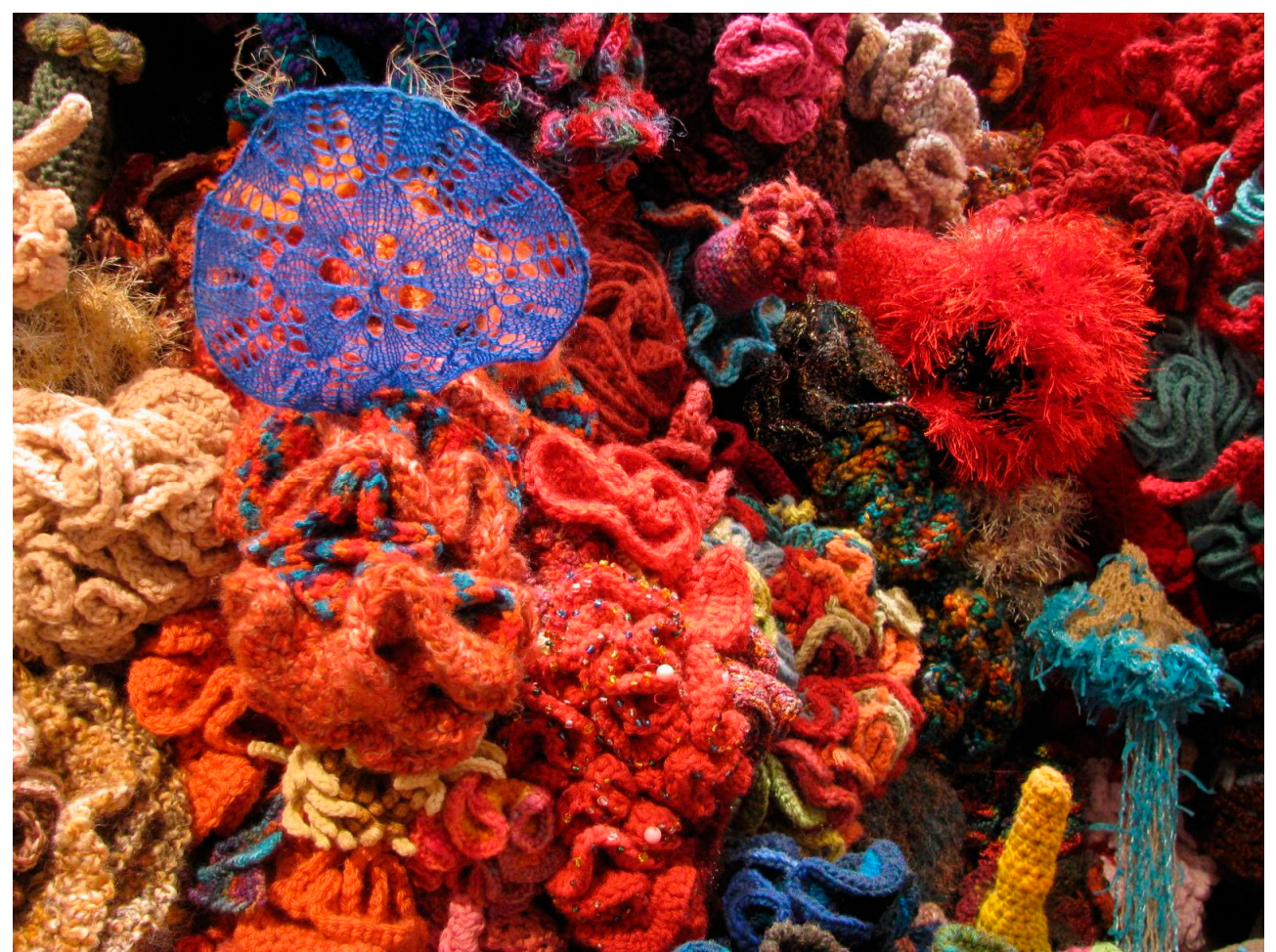

Figure 3. Detail of Hyperbolic Crochet Coral Reef exhibit at the Smithsonian's National Museum of Natural History in Washington, D.C., 2010 (Photo by otandka https://www.flickr.com/photos/27498524@ N00/5875436560/).

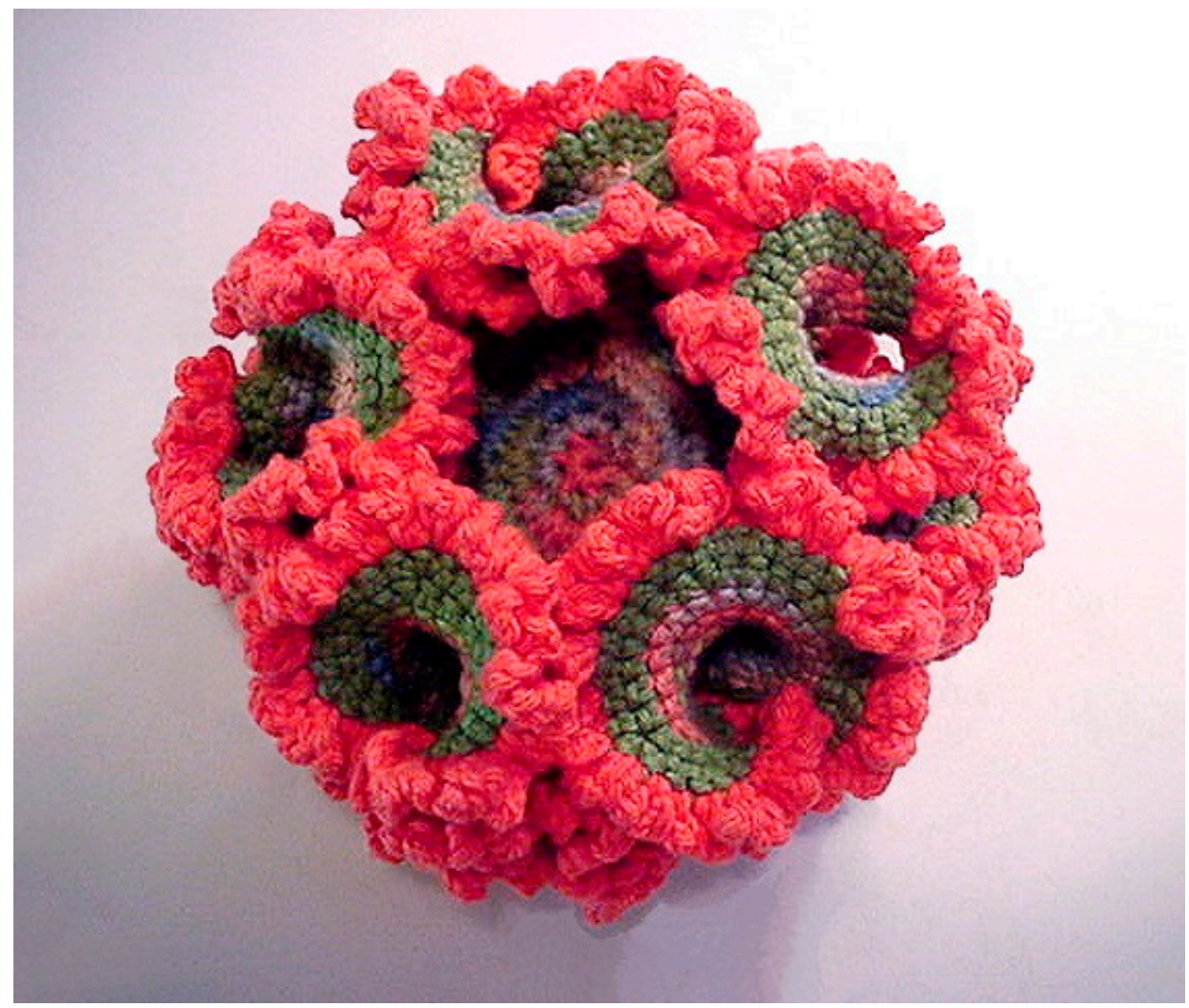

Figure 4. Detail of crocheted hyperbolic pseudosphere coral by Cheryl, 2011 (Photo by Cheryl https://www.flickr.com/photos/eraphernalia_vintage/5625775909/). 


\subsection{A Case for Hope}

The text definitions of hope from secular and theological perspectives initially appear remarkably similar, but upon further investigation have one significant difference. In the Merriam-Webster Dictionary, ${ }^{5}$ hope is described as to cherish a desire with anticipation, to want something to happen or be true, or to desire with expectation of obtainment or fulfillment. This appears to be nearly identical to the description in Baker's Evangelical Dictionary of Biblical Theology (Baker's Evangelical Dictionary of Biblical Theology 1897c), which is to trust in, wait for, look for, or expect something beneficial in the future. A major difference begins to emerge upon further inspection of these two understandings of hope. That difference is that a Christian understanding of hope is in trusting the promises of God that declare inevitable victory where things will eventually work together for good (Romans 8:28). This can be thought of like skipping ahead to watch the end of a movie and then rewinding to the beginning. You still wait and have hope for particular events to unfold within the movie, but there is the significant additional knowledge of what will eventually be, even if the path to that destination remains unclear. Since both a secular and theological approach to hope entails a desire in the present moment for eventual fulfillment, a new materialist framework can support a cross-discipline discussion and understanding of hope by addressing entanglements and intra-actions (Barad 2007) as well as the actual and the virtual (Deleuze and Guattari [1980] 2005).

The patient desire for a particular outcome of fulfillment remains similar to understandings from both secular and theological descriptions in addressing hope within a new materialist framework. In constructing Affirmative Ethics within a new materialist framework, Braidotti (2019) is clear on the emphasis of hope when she states "I have defended affirmative ethics as a collective practice of constructing social horizons of hope" (p. 156). In entangling hope with a new materialist framework, I argue that hope is to desire, anticipate, or expect fulfillment of a particular actualization of the virtual. What becomes highlighted here is the desire of the real in the virtual, which has yet to be actualized. This immanent yet-to-be of the virtual is entangled with the present moment and becoming of matter. Thus, as differences emerge through the intra-actions of the present, the virtual is reorganized for new potentialities that we can desire for fulfillment. This is significant regarding an artwork's force that produces new ways of seeing and understanding by producing new potentialities in the virtual (Atkinson 2017). Here, art's ability to influence the virtual is also understood to alter one's pedagogy and what one may hope for as new potentialities emerge, which will be explained in further detail later.

One example of exploring hope in a new materialist framework through the arts can be found in Joni Boyd Acuff's (2020) discussion of Afrofuturism in art education. Afrofuturism is a term created by Mark Dery (1994) to describe:

Speculative fiction that treats African-American themes and addresses African-American concerns in the context of twentieth-century technoculture-and more generally, African-American signification that appropriates images of technology and a prosthetically enhanced future. (p. 180)

Entangling Afrofuturism writers and artists, including but not limited to the writings of Eshun (2003), Love (2019), Mayer (2000), Morris (2012), Nelson (2000), and Yaszek (2006) alongside the art of Mickalene Thomas, Mark Lomax, Jean-Michael Basquiat, Stephen Hamilton, and Marvel's blockbuster film Black Panther, Acuff (2020) details how engaging with certain media and language in art can enable Black students to "envision their futures" (p. 16). Acuff is also specific to note that engaging with art in this manner is not liberal multiculturalism that typically makes art visible and leaves Africa in the past.

An example of an artist whose artwork explores material and the future in an Afrofuturistic manner is Nick Cave. Cave's artworks are inspired by African art traditions and investigate how material can create new relational understandings. For example, his Soundsuit series (Figure 5) consists 
of costumes that completely cover an individual, creating a second skin that obscures previous representationalist understandings of individuals such as race, gender, and social class. Notably, Nick Cave's first Soundsuit was created in 1992 as a demonstration against the beating of Rodney King (Gallagher 2017). In a new materialist understanding, Cave's Soundsuits challenge racist and sexist paradigms by engaging with African art traditions and materials to create a relational difference with individuals that breaks from representationalism. In this way, Nick Cave's Soundsuits can be understood to create a difference of hope where individuals are not punished for a dualistic concept such as race.

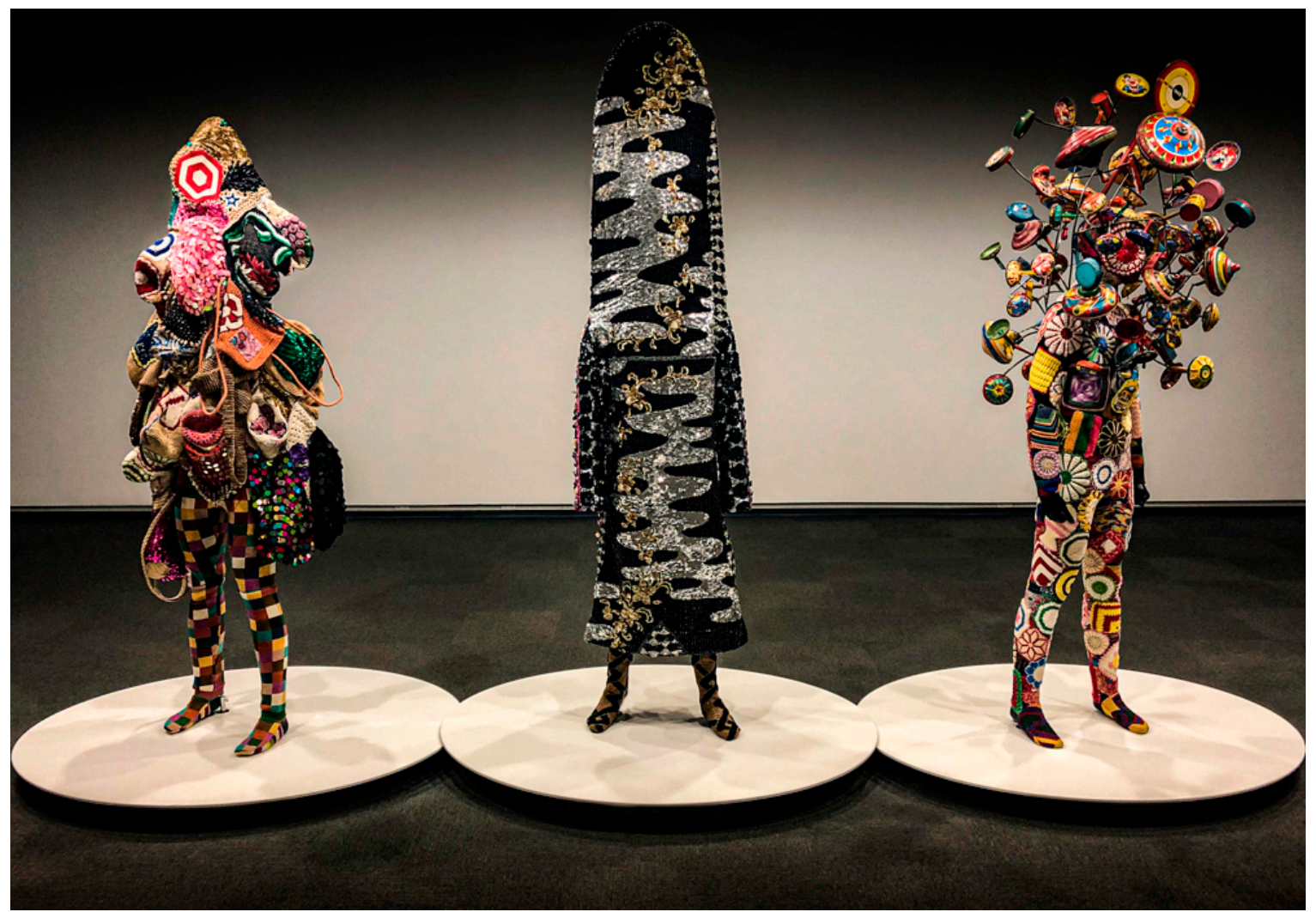

Figure 5. Nick Cave Soundsuits (Photo by Chris Friese https://www.flickr.com/photos/free-zee/ 48227357961/).

By entangling Afrofuturism in education, focus becomes "not only to provide our students with access to the arts, but to demonstrate how the arts can be used to access the future" (p. 20). Here, a new materialist understanding of hope can be identified in the entanglement of Afrofuturism art with students encouraging exploration of new possibilities in the virtual alongside the actualization of artmaking (Atkinson 2017), which provides ruptures for new ways of seeing and knowing. Hope is a significantly needed as Acuff (2020) accurately notes the cultural climate includes a barrage of viral and news videos where we see:

Young Black women slammed to the ground by police officers; Black trans-gender women violently assaulted and murdered in the streets; unarmed Black men and boys shot inside their homes, backyards, and schools; and churches and synagogues ambushed and sprayed with bullets by White domestic terrorists. (p. 13)

Since the acceptance and publication of Acuff's (2020) article, the police murder of George Floyd in Minnesota has incited cultural movement regarding anti-racism and police brutality, involving protests across the country as well as international protests including the United Kingdom, Germany and Canada (Hagemann 2020). Cultural distress, including but not limited to issues of social and 
racial justice, can be approached in terms of a culture war in which a group fights for dominance, or in terms of "culture care" (Fujimura 2017) from which an entangled understanding that we are all in this together emerges. It is this within the latter perspective of culture care that a new materialist understanding of the arts can actualize cultural stewardship through mercy, grace, and hope.

\section{Art as Ethical Stewardship}

Braidotti's (2019) work seeks to answer her question: "how can we work towards socially sustainable horizons of hope, through creative resistance" (p. 19). In addressing this question through the arts in a new materialist posthuman paradigm, Braidotti advocates for what she calls the Critical PostHumanities. In this argument, Braidotti states that "thinking and knowing are not the prerogative of humans alone, but take place in the world" (p. 101), which highlights the entanglement of matter and a posthuman understanding. Furthermore, within the Critical PostHumanities, there is a drive to mending the "disjunction between major and minor science" (p. 161), in which "major science is sedentary and protocol bound, minor science is situated, perspectivist and able to combine critique with the creation of new concepts" (p. 126). This focus is reflective of the convergence of the posthuman condition, removing barriers between various fields of knowledge in support of a "supra-disciplinary" quality (p. 102). In the spirit of exploring a supra-disciplinary character of arts for ethical stewardship, publications from new materialism, art education, and theological perspectives are entangled, allowing for a diffractive analysis and united approach to understanding how the arts can be a steward to actualize ethical becomings.

The arts create experiences through materials, forming a logical connection for adopting a new materialist perspective that is a focus on matter. New materialism within art education is not limited to human-made objects; consequently, new materialism should not to be confused with material culture, which "is generally regarded to comprise the purposefully constructed or intentionally acquired things we encounter, as well as the human-made spaces within our world" (Blandy and Bolin 2018, p. 7). Instead there should be a focus on recent art education publications within a new materialist framework that frequently cite the work of Karen Barad (2003, 2007). Here, authors are addressing the complex entanglements of matter to explain how students, teachers, and artworks emerge in art classrooms (Atkinson 2017; Garber 2019; Guo 2017; Kaplan 2019; Keifer-Boyd 2018; Leonard 2020; Rech Penn 2019; Schulte 2019).

One notable publication in this emerging new materialist art education body of work is the book Art, Disobedience, and Ethics by Dennis Atkinson (2017). This literature is significant to the present argument as it entangles the new materialist theory of Barad (2007) with the force of art (Ziarek 2004) and concepts of relations and ethics including but not limited to Deleuze and Guattari (Deleuze and Guattari [1980] 2005), Spinoza (1996), and Whithead (1978). In forming this entanglement, Atkinson refers to disobedience as "an event of non-compliance that opens up new ways of thinking and acting." (p. 195). In constructing his argument for a new materialist pedagogy in art education, Atkinson explores how learning events and encounters with art "generate the force to disrupt or challenge established ways of seeing, forms of representation or established modes of affect and precipitate new sensibilities and ways of seeing and thinking" (p. 124). In this way, encounters with art can provide a line of flight for disobedience from dominant paradigms to create new relations (Aulich and Ikoniadou 2020).

Such encounters with art are of ethical concern as new possibilities emerge in becoming with the world, what Haraway (2016) termed response-ability. Such focuses on entanglements brought forth from an art encounter are succinctly described by Atkinson (2017):

The transformative event of art's forcework, of art's poietic materiality, points towards a world beyond art, to practices and a people yet to come, and it does not lie in art's ability to criticise, but to the event of a world becoming otherwise or pointing towards such possibilities. (p. 161) 
Since these encounters with art direct focus toward the virtual, new materializations and sensibilities can emerge in the world once actualized. Describing this tension of how art is always on the edge of influencing the world's becoming, Atkinson (2017) claims that "the force of art is always in the middle between the virtual and the actual" (p. 148). In this manner, Atkinson continues to summarize how the matter of art creates ruptures, allowing for disobedient ways of knowing and becoming with the world. In this sense, encounters with artworks create entanglements that provide an opportunity for an ethical engagement with the world for better becomings.

Other art educators have also supported this concept that "making art that has the capacity to transform us, and thereby change the world around us" (Sullivan 2006, p. 223). Further supporting this point, neuroscience studies have also noted that contemplating art promotes better self-understanding, social knowledge, and empathy (Sherman and Morrissey 2017). One seminal work to arts' transformative qualities is Releasing the imagination by Greene (1995). While this work has an intended focus on education and directly challenges postmodern thinking, her critical insights recognizing multiple forces in action can be expanded to begin addressing the non-human as well as the human. Entangling Greene's work with new materialist theory for diffractive reading produces new potentialities for the visual arts to emerge as a significant form of ethical behavior and influence.

In a similar way to how Barad (2007) and Braidotti (2019) highlight the entanglement of humans and nonhumans in an embedded and embodied coexistence with a focus on ethics for better becomings, Greene (1995) argued that "once we can see our givens as contingencies, then we may have an opportunity to posit alternative ways of living and valuing and to make choices" (p. 23). Greene's work is also ethically concerned, as it suggests actions for improved futures rely on individuals making decisions "in the light of their lives with others" (Greene 1995, p. 198). Furthermore, Greene's work advocates for a form of positive ethics that is brought forth by those with "imaginative awareness that enables those involved to imagine alternative possibilities for their own becoming and their group's becoming" (p. 39). Since imagination makes empathy possible, Greene strongly advocates for the arts throughout her writing. This can draw parallels to Braidotti's Affirmative Ethics that supports, "Artistic practices for defamiliarization, non-linearity, the role of figurations, and critical thinking" (pp. 132-33).

Further entangling ethics with artistic making is the work of Christian artist Makoto Fujimura (2017). While his statements are not from a posthuman perspective, they introduce a theological perspective of artmaking and ethics worth diffractive reading against the works of Atkinson (2017), Greene (1995), Barad (2007), and Braidotti (2019) in the spirit of cross-discipline discussion. In his book titled Culture Care: Reconnecting with Beauty for Our Common Life, Fujimura made a strong argument for artists as cultural stewards. Fujimura states that "artists have a deep capacity to develop and share generosity and empathy, to point toward abundance and connections" (p. 19) because they have an ability to "lower the barriers for understanding and communication between cultures" (p. 58). Statements like these clearly show an anthropocentric perspective that contradicts new materialist theory.

Despite a human-centered approach, further investigation into the work of Fujimura (2017) highlights a strong recognition of the relationship of humans and materials in the artmaking process. For example, Fujimura states that:

In anything we make, we bring our creative energies, but we are always acting in stewardship of something that we have been given. At our best we work with our raw materials, honing their properties and respecting their limits, not working against the grain or twisting them out of context. In short, we need to love both nature and culture to exercise proper stewardship.

This recognition of material, while not being new materialist, is also clearly found in his selected detailed example of culture care. In this example, he highlights shared human and nonhuman forces, entangling Fred Danback, the Hudson River, a copper wire factory, parks, and student population 
(Fujimura 2017). A nod toward an entangled understanding of what matter may become is also provided by Fujimura in discussing a tree when he states, "what emerges from generative moments is something new, transformed from its source, something that is both free and responsible to make its own ongoing creative contribution" (p. 24). In summary of Fujimura's (2012) philosophy, he acknowledges the force of art within a theological context stating that "if we do live in a visual culture, then lack of beauty leads to a dehumanized state of our entire culture; and, I might add, poverty of our theology." In this line of thought, experiences with the beauty of art along with "interactions with our physical and cultural environment directly affect our bodies, our minds, and our spirits, and ultimately our souls" (Fujimura 2017, p. 29).

In conclusion, the event of artmaking or experiencing art can be an ethical act of cultural and environmental stewardship. This argument was constructed by entangling Braidotti's (2019) new materialist Affirmative Ethics and Critical Posthumanities, with Atkinson's (2017) discussions on the force of art, pedagogy, and disobedience, alongside Fujimura's (2017) philosophy of beauty and artmaking as culture care. In bringing these texts together, a diffractive reading can take place to investigate how cross-disciplinary discussions (Polkinghorne 2010; Van Huyssteen 2006) can emerge along with their natural limits of difference. To further illustrate how artworks can be approached with a new materialist framework to address stewardship through mercy, grace, and hope, two artworks are discussed: Becoming Us by Megan Constance Altieri and the Teeter-Totter Wall by Ronald Rael.

\subsection{Becoming Us}

Megan Constance Altieri (2020) is an artist, author, and art educator currently residing in Grand Rapids, Michigan, whose award-winning artwork focuses on relationships and identity. Becoming Us by Altieri was selected as an example to break away from prior ways of thinking about matter in art, specifically through material culture (Blandy and Bolin 2018), that can impose certain rhythms and transcendent operators to limit understandings and potentialities for learning (Atkinson 2017). After a brief overview of Becoming $U s$, this section addresses how the temptation to apply a material culture understanding can potentially limit the force of art and how a new materialist perspective can change the experience of engaging with this artwork to create new possibilities in the virtual.

Becoming Us was part of the Good Manufacturing group exhibition titled "Proof of Thought" that took place at the 106 Gallery in 2018 (Figures 6 and 7). The art installation consisted of various objects suspended throughout a room from various colored threads connecting to photographs of individuals located around the perimeter of the room. Altieri (2020) describes these objects as "the physical embodiments of our unfolding identities could be seen through our affinity towards certain clothing, hairstyles, makeup, or body shapes." Further investigation into the art piece's concept and symbolism reflected in these materials details these objects were selected to define the coming of age epochs of individuals who have come to identify as LGBTQ+. To this point, Altieri states that:

The suspended objects serve as relics of the sweeping internal battles and revelations occurring throughout these epochs. Each relic is connected by colored thread, saturated in relation to the level of clarity we experienced during those seasons of becoming us. (2020) 


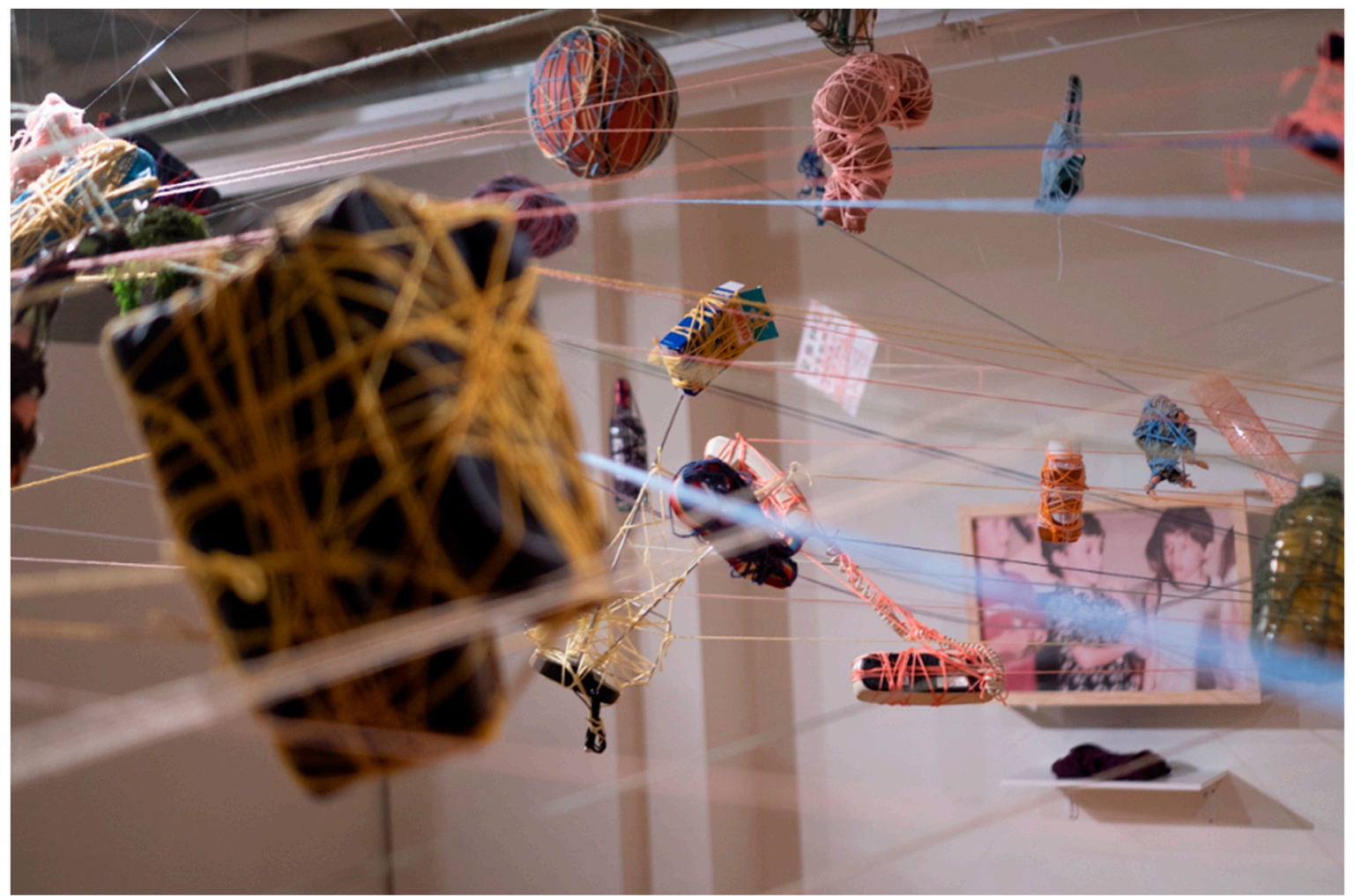

Figure 6. Detail photo of suspended objects in Becoming Us, 2018 (Photo graciously provided by Megan Altieri).

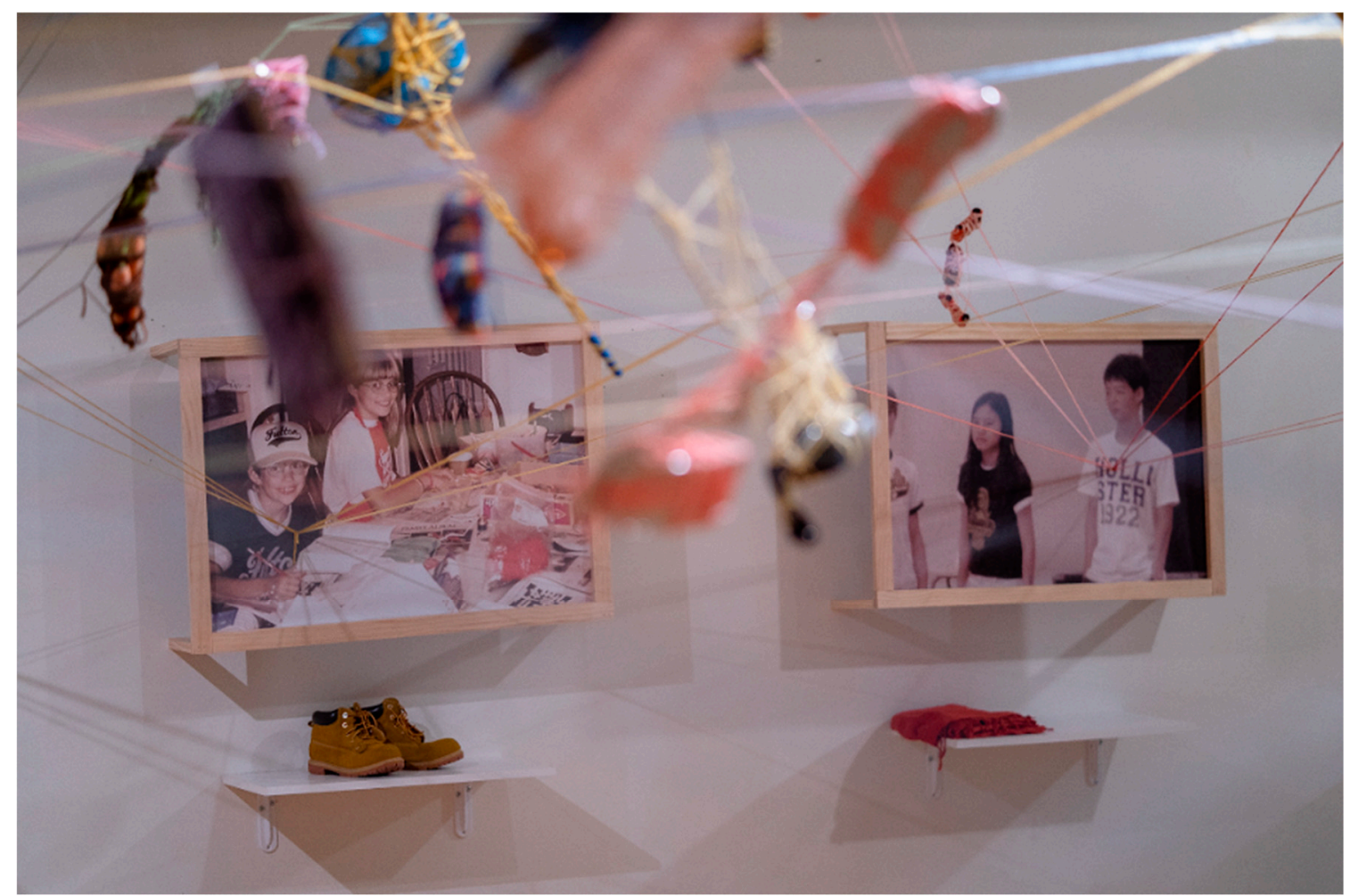

Figure 7. Detail photo of thread connecting to portraits in Becoming $U s, 2018$ (Photo graciously provided by Megan Altieri). 
By displaying these private struggles through entangled material, a shared community experience exploring perspectives and growth can begin to remove negative connotations. In this way, the artwork simultaneously creates and blurs a linear narrative of the objects that have come to have significant meanings for the struggles endured by various LGBTQ+ individuals in their becoming and points toward a positive future becoming.

The symbolism expressed in this artwork is significant and strongly aligns with a material culture perspective. Recalling that material culture is "a descriptor of any and all human-constructed or human-mediated objects, forms, or expressions, manifested consciously or unconsciously through culturally acquired behaviors" (Bolin and Blandy 2003, p. 249), the relics in Becoming Us can clearly be understood to represent and express a human-centered values reflective of personal stories and struggles. This point was further clarified through personal communication with Megan Altieri when she commented:

The installation invites the viewer to engage in three different ways with the commonplace artifacts in the work. Viewers might respond to their operative function, their nostalgic significance, or to their assigned significance as illustrations of the stories. The multifaceted invitation opens the heart of the viewer to empathize fully with these subjects and their stories. ${ }^{6}$

In this way, Becoming Us encourages approaching the objects and stories according to Blandy and Bolin's "Five Fundamental Beliefs about the Intertwined Nature of People, Stories, and Objects" (Blandy and Bolin 2018, p. 36), in which objects are seen to shape us, creating stories in which the object has a meaningful significance to an event. These material culture approaches to Becoming Us can invoke an emotional response to engage with other perspectives and empathy, but a new materialist framework focusing on art as stewardship can create new possibilities for mercy, grace, and hope in ways not provided by a material culture framework.

While addressing the force of art and pedagogy from a new materialist and posthuman perspective, Atkinson (2017) argues that "pedagogic work was to avoid or reduce the controlling force of those transcendent operators of established practice that might delimit actions and therefore miss the generative event of learning" (p. 166). Previous understandings and habits can limit new forms of engagement. A material culture approach is seen as a transcendent controlling force to which a new materialist approach can expand possibilities for engagement and intra-action. In her new materialist theory of Agential Realism, Barad (2007) argues for addressing matter in the continual process of becoming to emphasize and recognize how differences emerge rather than reflect previous understandings. Thus, Becoming $U s$ is not just a physical collection of human-centric objects in an artistic installation to be read for a particular meaning, but an entanglement of matter that creates new potentialities in the virtual for possible actualization.

In the proposed new materialist approach, the objects suspended in the Becoming Us installation do not pre-exist its intra-action with an observing apparatus. Furthermore, all matter is deemed significantly entangled with other matter rather than only acknowledging objects labeled with human significance. This deeper entanglement recognition of the art means that a phone (Figure 8) should not be read for a pre-existing story but should be recognized as matter that is also constantly in the process of becoming that has created, and continues to create, differences in the world. The particular entanglement of the Becoming Us artwork can be understood as matter that has made a difference to other subjects just as they continue to make a difference to the observer. What potentialities in the virtual were actualized through the phone and, in its current entanglement, what new differences are made in the continuously unfolding of the world? I argue that this perspective not only aligns with the original empathetic and healing intention of Becoming Us, but it goes further by bringing 
significance to the matter itself by highlighting the embodied and embedded becoming of all humans and nonhumans for mercy, grace, and hope.

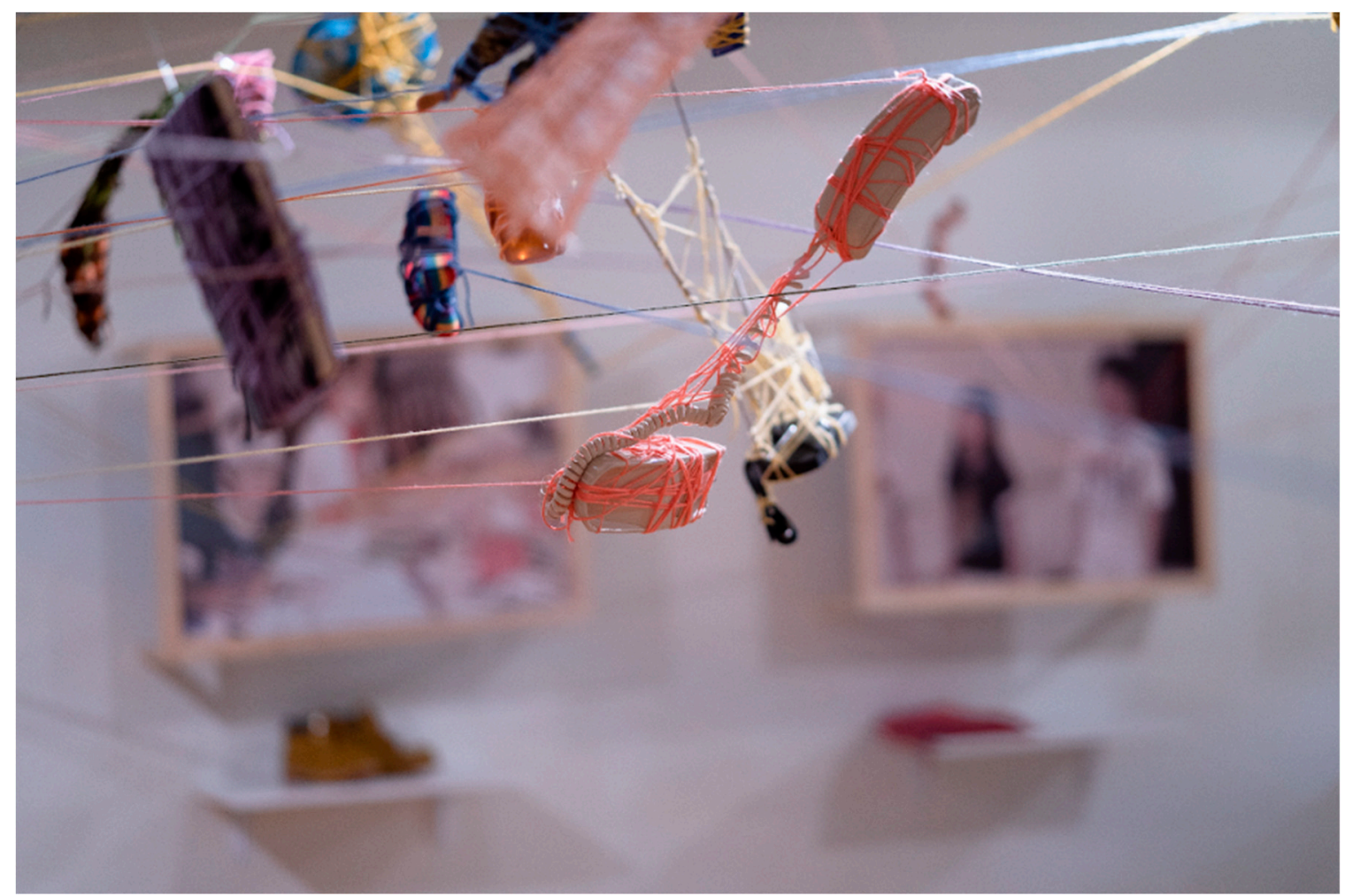

Figure 8. Detail photo of a phone entangled in Becoming Us, 2018 (Photo graciously provided by Megan Altieri).

Mercy is a recognition that you are entangled with the development and becoming of the other, in which an act of compassion to withhold negativity or pain is made to actualize positive transformation. While still recognizing the material culture intent of Becoming $U s$ to remove confusion and negativity, a new materialist perspective can provide new opportunities for engagement and understanding to further better becomings through mercy. The dynamic flows and becomings in the world from which Becoming Us emerged includes many specific entanglements in which various subjects experienced pain in their becoming. Here, the phone should not simply be assumed to represent a phone call, but is a deeper entanglement in which the phone was matter intra-acting within a specific event to create new potentialities. By literally entangling the phone in colored thread along with many other objects, the matter constituting what many would recognize as a phone is intra-acting in a new context, allowing for a rupture from previous understandings. In doing so, a human-centric view that an individual person used the phone for a significant call to another person is expanded to recognize the complexities of what potentialities emerge and organize in the virtual due to entangled matter. Thus, Becoming Us displays mercy by withholding and perpetuating just anger and negativity from events from LBGTQ+ becomings by presenting the becoming of the matter, such as the phone, in new entanglements where the material's becoming can create possibilities in the virtual for positive transformation.

Recalling that by observing all matter as dynamically becoming in a new materialist framework, grace can be understood as the unmerited application of favor or kindness to actualize better becomings. A focus here should be given to the unmerited quality of grace where there is no expectation of kindness so an expression of kindness within an entanglement becomes an action of grace. By acknowledging that:

The past is not a frozen block of half-accomplished deeds, but a heterogenous mass of future pasts awaiting historical actualization. And likewise, the future is the on-going unfolding of an unrealized virtual past. (Braidotti 2019, p. 65) 
Becoming Us displays grace by entangling painful future pasts for better becomings. Put another way, without being required or requested, the artwork embodies acts of kindness in which painful pasts were willingly gifted into an artistic entanglement for the actualization of better becomings. This new materialist observance of grace is significant since it simultaneously recognizes the becomings of others while recognizing that the observer is equally entangled and response-able in the continuing becoming of others, human and nonhuman.

Furthermore, Becoming Us conveys hope. Recognizing that through a new materialist framework, hope can be understood as to desire, anticipate, or expect the fulfillment of a particular actualization of the virtual, the art installation Becoming Us embodies hope by forming new potentialities in the virtual for a deeper acknowledgement of shared becomings. Since the intra-actions of the actual create new possibilities in the virtual, the recognition of complex entanglements supported by the objects and colored threads in Becoming Us directly challenges observers to question their status as an observer who is not embodied and embedded in the artwork they observe (Figure 9). Here, a difference emerges between a new materialist hope and a human-centric material culture hope. In Becoming Us, the material culture hope could be identified through the artist quote that:

In giving these anecdotes space and perspective, we have untangled the threads of our histories, rid them of the confusion or negativity they once held, and most of all, found comfort in the overlap between them. (Altieri 2020)

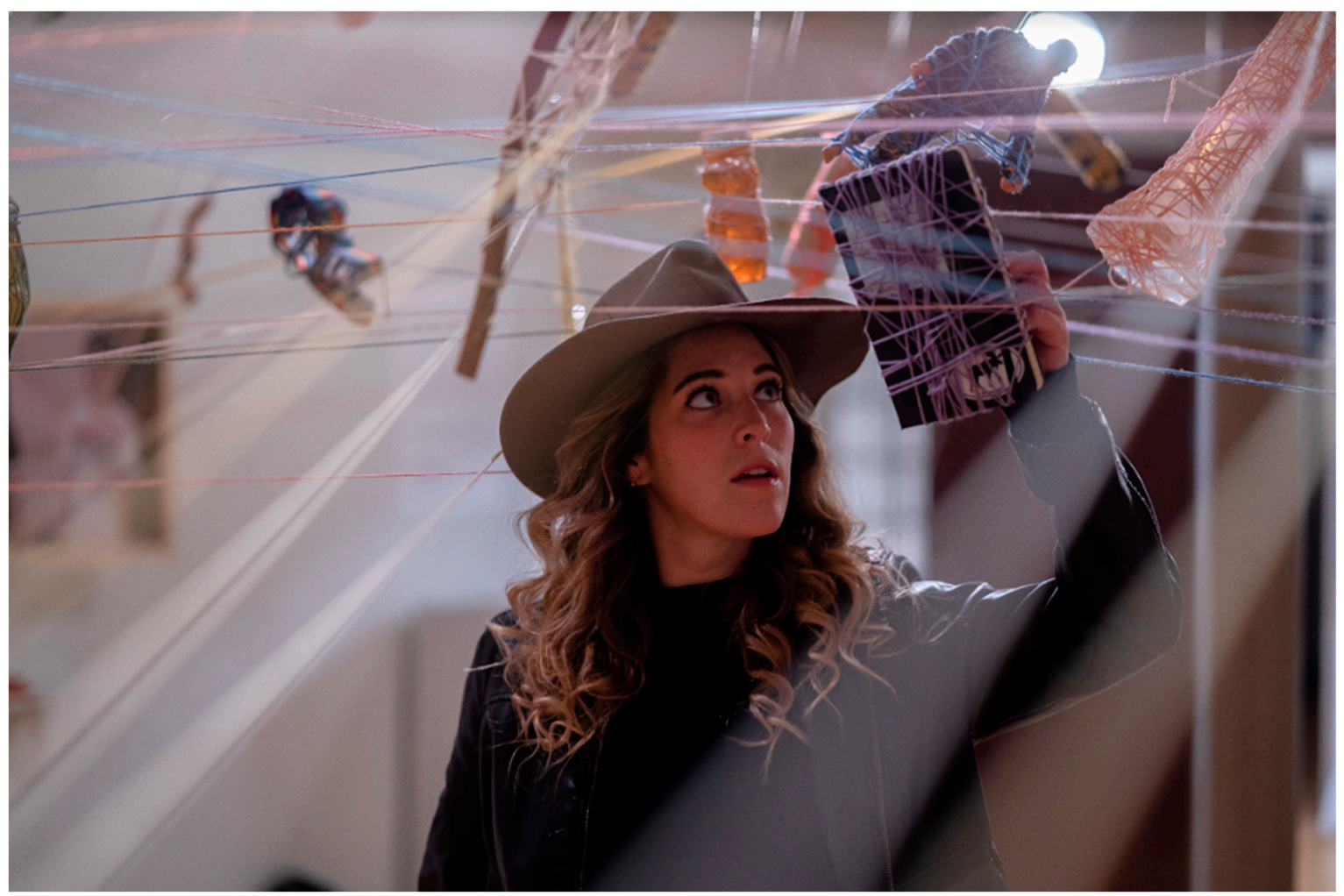

Figure 9. Megan Altieri inspecting Becoming Us, 2018 (Photo graciously provided by Megan Altieri).

Here, the focus on the healing of individuals represented in the artwork through community and fellowship is significant. By applying a new materialist framework, the focus still involves those individuals but expands the entanglement to explore hope for what we are all becoming together, human and nonhuman, and our response-ability (Haraway 2016) in that process.

By addressing Becoming Us from a new materialist framework focusing on mercy, grace, and hope, the Becoming Us can be understood as a form of stewardship. This is accomplished by presenting a framework to recognize both the force of art and matter in its perpetual becoming in which the 
observer is also entangled. Here, the focus on intra-actions within art material entanglements has been detailed to contrast a human-centered, symbolic, material culture approach. Through Becoming $U s$, negativity is withheld, kindness is displayed, and new potentialities in the virtual are created for hopeful becomings. In recognition of the qualities of mercy, grace, and hope being actualized through this artwork, Becoming $U_{s}$ is an exemplar artwork for new materialist stewardship.

\subsection{Teeter-Totter Wall}

Ronald Rael is an acting chair and professor of architecture and art practice at the University of California, Berkeley. In 2017 Rael published a book titled Borderwall as Architecture: A Manifesto for the U.S.-Mexico Boundary in which he artistically explored the entanglement of the border wall and the potential becomings that could provide "opportunities for the residents of this landscape to intellectually, physically, and culturally transcend the wall through their creativity and resilience" (p. 5). While this publication does not directly state a new materialist or posthuman theoretical framework, it provides helpful insight into observing his 2019 border wall installation Teeter-Totter Wall (Figures 10 and 11) created with partner Virginia San Fratello and other supporting artists (Brice 2019). What follows is a suggestion for a new materialist intra-action with the Teeter-Totter Wall to explain the force of art for stewardship through mercy, grace, and hope.

Borderwall as Architecture (Rael 2017) emerged as part of a pitch to Washington, DC, lawmakers to explore new considerations about the border wall and its construction. While it appears that the current administration has disregarded this pitch, Rael's work:

No longer seeks to intervene in the wall's construction, but instead to consider its transformation - an expanded study on rethinking existing wall by redesigning it into something that would exceed its sole purpose as a security infrastructure and ameliorate the wall's negative impacts and perhaps through intervention, make positive contributions to the lives and landscapes of the borderlands. (p. 4)

While this stance is not specifically new materialist, it provides a strong foundation for beginning to address art installations such as the Teeter-Totter Wall for the concepts of mercy, grace, and hope.

The Teeter-Totter Wall was installed in 2019 on the borderwall between Puerto de Anapra, Mexico, and Sunland Park, New Mexico (Barajas 2019; Brice 2019). The installation consisted of three neon pink metal teeter-totters, also commonly referred to as seesaws, not much different than those one may encounter at a public playground. These teeter-totters were constructed in Mexico and then brought to the border where the beams were slid between, and then attached to, the vertical beams of the border wall. The seats and handles were then attached to the teeter-totter beams to create three functional teeter-totters with one seat located within the U.S. and the other seat in Mexico.

In describing the work, Rael (2017) states that "perhaps the best way to represent the mutually dependent relationship between the United States and Mexico is through the construction of a Teeter-Totter Wall" (p. 105). Here, there is a clear symbolistic meaning in that the hinges of the teeter-totter can reflect the hinges of the relationship between the U.S. and Mexico. While these interpretations of the artwork provide rich and engaging material, a new materialist approach to this artwork provides new lines of flight for understanding the artwork's entanglement to humans and non-humans for actualizing the concepts of mercy, grace, and hope. 


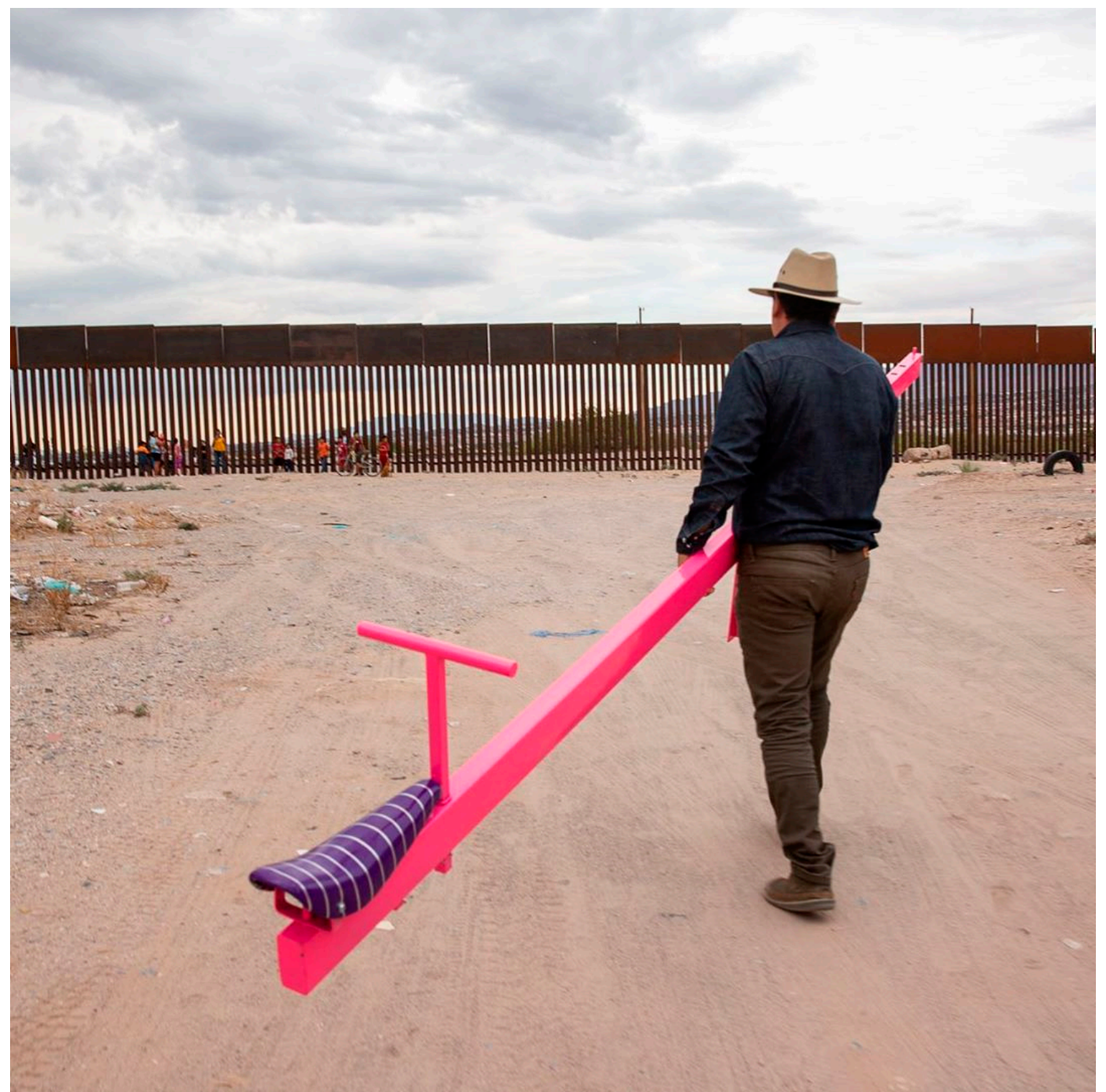

Figure 10. Ronal Rael walks up to border wall to install artwork (Photo graciously provided by Ronal Rael).

In the Teeter-Totter Wall entanglement, the border wall is not a finished object; instead the border wall is simply matter. Since all matter is in the process of becoming, the metal pushed vertically into the dirt is transformed through the various intra-actions with other matter. Transcendent operators including, but not limited to, national, racial, and economical division are disregarded to explore what differences emerge in the moment of becoming. When the neon pink metal teeter-totter beams entangle with the border wall, the apparatus for engaging with this matter is dramatically shifted, creating the possibility to establish conceptions of practice and the potential to create new worlds of practice (Atkinson 2017, p. 139). What differences are made in this artwork and how can these differences be attributed to the concepts of mercy, grace, and hope? 


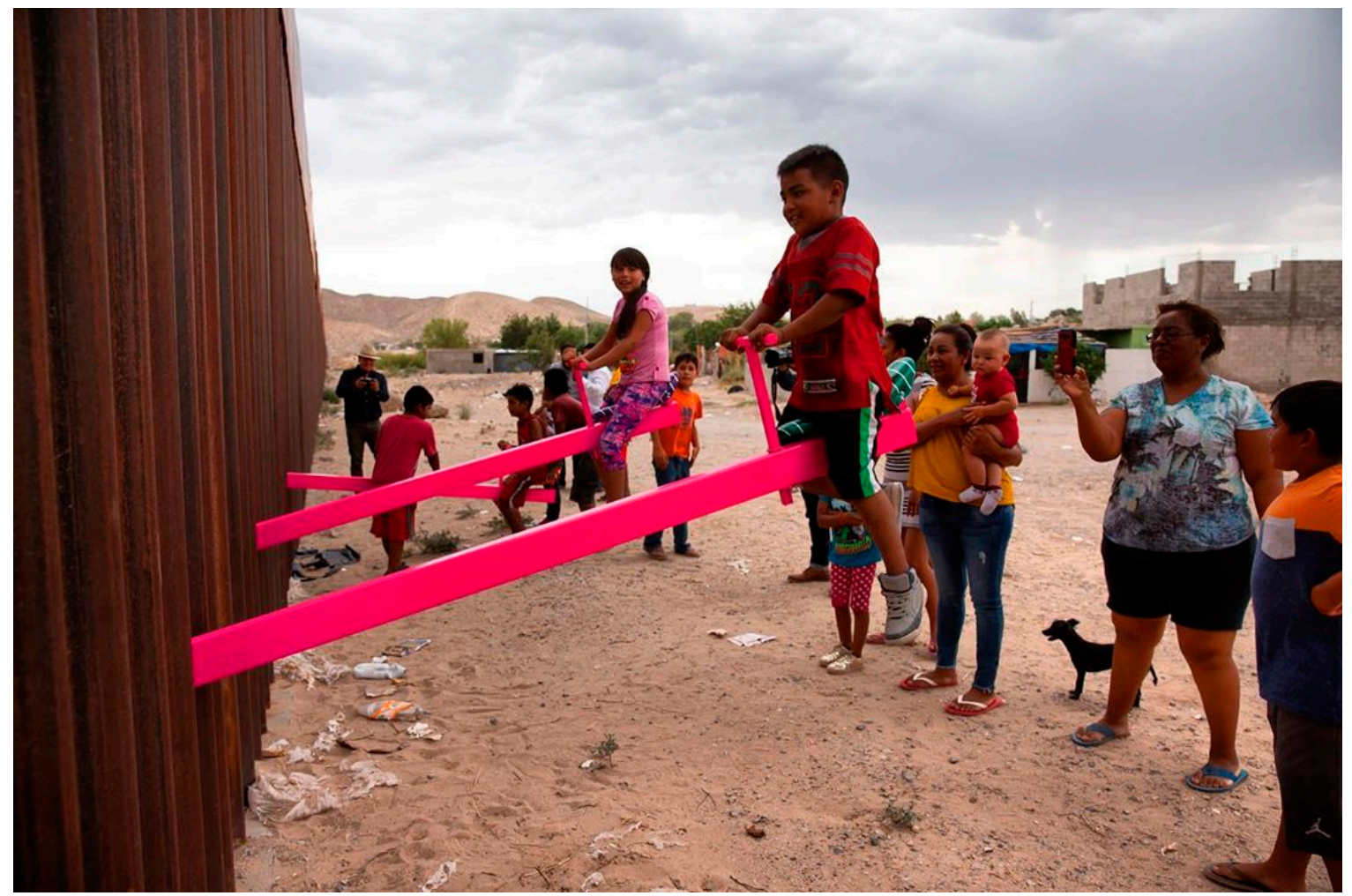

Figure 11. Children playing with installed teeter-totter (Photo graciously provided by Ronal Rael).

Recalling that mercy is a recognition that you are equally entwined with the development and becoming of the other and an act of compassion could be to withhold justified negativity and pain to actualize positive transformation, how then does Teeter-Totter Wall actualize mercy? For there to be mercy, there must also be judgment. Some judgments that can be identified within the Teeter-Totter Wall include judgments regarding the defensive, societal, and environmental value and impact of the border wall. Without justice, the impacts of mercy and grace are diminished. Within this entanglement, the actualization of the wall in its construction has already emerged and altered the field potentialities in the virtual. Thus, the next judgment is: what should become of the matter observed to be the border wall? If constructing the wall was not just, then one possible judgment could be to punish the wall through its destruction. Making a judgment against the construction of the border wall does not result in its just destruction; the Teeter-Totter Wall shows mercy by withholding punishment. This act of compassion does not avoid or deny the negativity and pain actualized by the border wall but instead works to "transform its negative charge" (Braidotti 2019, p. 167) for a better becoming.

Furthermore, the Teeter-Totter Wall can be understood to display grace. If grace is showing favor when there is no warrant or expectation of such action, how can the Teeter-Totter Wall display grace? Remember that by observing all matter as dynamically becoming, grace is the unmerited application of favor to actualize better becomings, and justice must again be briefly addressed to identify what is merited to display the power of grace. If it is just that there is no expectation of kindness, then any expression of kindness is a graceful action. The artwork was an installation between Puerto de Anapra, Mexico, and Sunland Park, New Mexico, which encouraged engagements from human residents on both sides of the border. These towns received an entanglement forming an actualization described by Rael as "Women and children completely [who] disempowered this wall for a moment, for 40 min. There was a kind of sanctuary hovering over this event" (Brice 2019) (Figure 12). Further detailing the event, Rael recounts the unexpected acts of kindness from the U.S. Customs and Border Protection as well as Mexico's National Guard displayed by watching the event, smiling, and taking photos (Figure 13). The Teeter-Totter Wall was an act of kindness toward both communities and the border wall 
itself and created an entanglement of grace where acts of kindness emerged, allowing for disobedient ways of knowing and becoming with the world (Atkinson 2017).

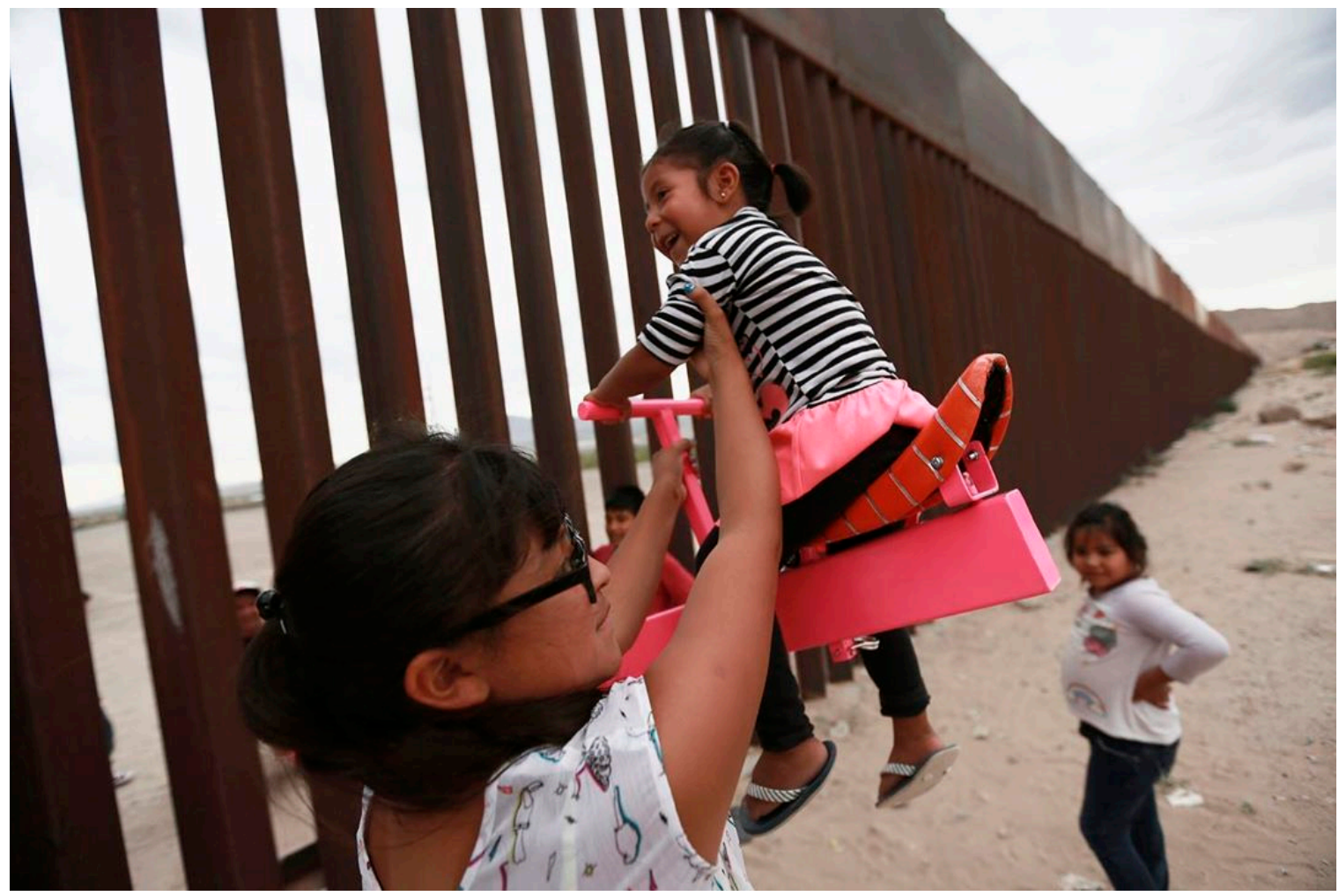

Figure 12. Young child playing with installed teeter-totter (Photo graciously provided by Ronal Rael).

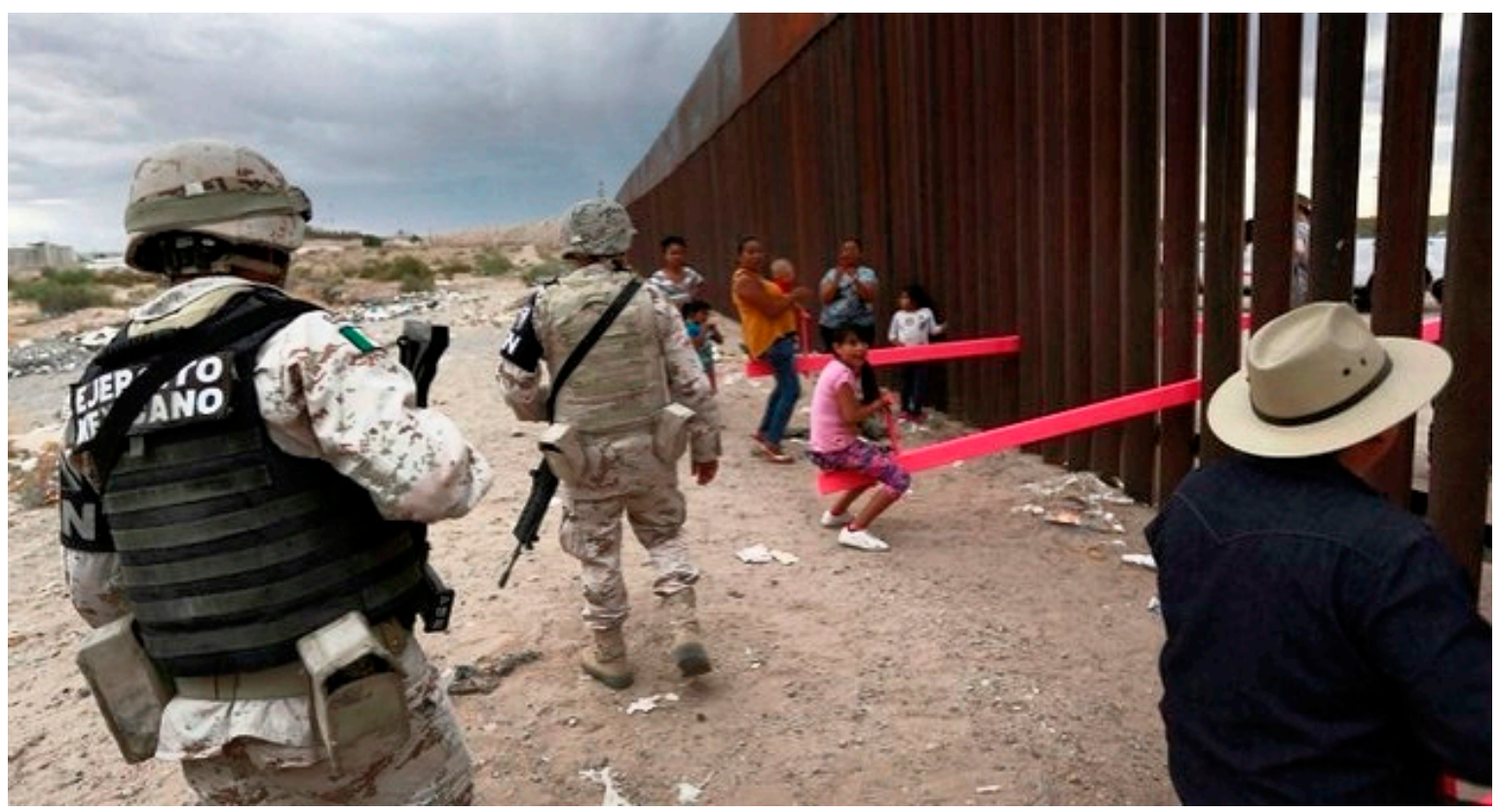

Figure 13. Border security observes art installation (Photo graciously provided by Ronal Rael).

Finally, the Teeter-Totter Wall displays hope though a new materialist framework. Recall that hope is to desire, anticipate, or expect the fulfillment of a particular actualization of the virtual, where the intra-actions of the actual create new possibilities in the virtual. According to Braidotti's (2019) "material immanence" (p. 38), there must be an acknowledgement of the solidarity with other humans 
and non-humans in our becoming. The Teeter-Totter Wall entangles the artists, local residents, the U.S. Customs and Border Patrol, Mexico's National Guard, the border wall, teeter-totter beams, along with various other political and art forces that can be thought of as the rhythms of becoming with, as referred to by Haraway (2016) as sympoiesis, or the territories and ritornellos (Deleuze and Guattari [1980] 2005; Kleinherenbrink 2015). As this artwork brings attention to the becoming-with of the human and nonhuman entanglement, opportunities emerge for thinking otherwise and creating "an event of non-compliance that opens up new ways of thinking and acting" (Atkinson 2017, p. 195). The Teeter-Totter Wall provokes and challenges what one hopes for in the becoming of the other by highlighting that "We-Are-All-In-This-Together-But-We-Are-Not-One-And-The-Same" (Braidotti 2019, p. 52).

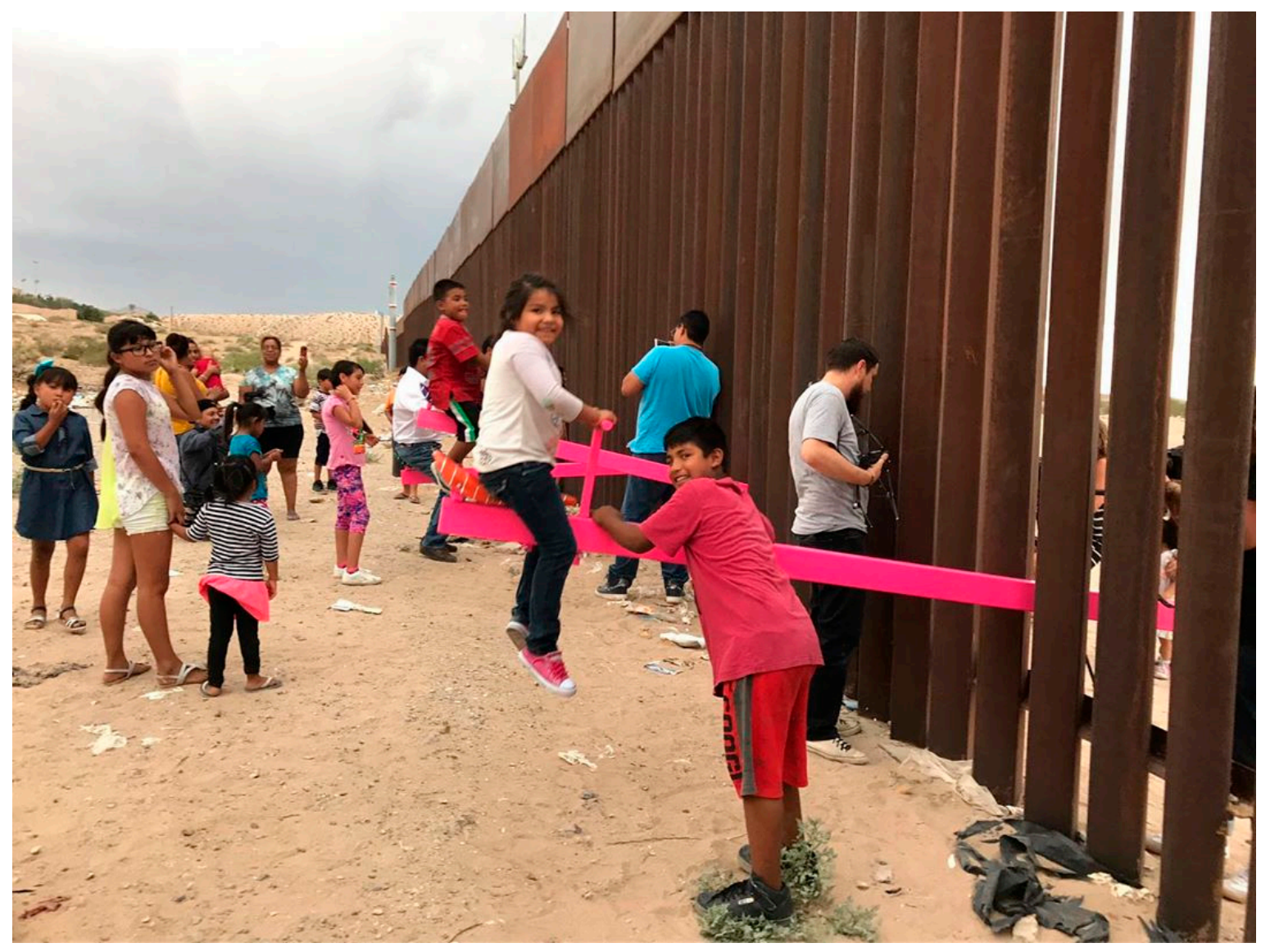

Figure 14. Two children play with installed teeter-totter (Photo graciously provided by Ronal Rael).

In addressing the Teeter-Totter Wall from a new materialist framework focusing on mercy, grace, and hope, the Teeter-Totter Wall can be understood as a cultural steward (Figure 14). Engaging with this work through a new materialist perspective, the term culture becomes understood to be more inclusive and include humans and nonhumans within the greater material entanglement of the world. Furthermore, by addressing the world's entangled becoming through mercy, grace, and hope, culture is not addressed as a limited resource that needs to be divided and fought over through culture wars. Instead culture can be better understood within the philosophy of "culture care" (Fujimura 2017, p. 22), where the force of art emphasizes culture as a shared entity to which we are all called to be stewards. Since artworks are dynamic engagements that can form new relations in the actual and influence the virtual for better becomings, art is of ethical and pedagogical concern (Atkinson 2017) and we are all entangled. The concepts of mercy, grace, and hope have been selected as an act of culture care to focus on the shared entanglement to the other, both human and non-human, and encourage healthy 
cross-disciplinary discussions (Polkinghorne 2010; Van Huyssteen 2006) toward better becoming in which we are all entangled.

\section{Conclusions}

To support the healing of our polarized culture through art, new materialist theory as presented by Karen Barad (2007) and Rosi Braidotti (2019) provides a framework to address art for transformative change and stewardship (Atkinson 2017; Fujimura 2017). Since influential political leaders in America are perpetuating confrontational dualistic thinking by creating binary understandings where the other is identified as a threat, a method for traversing these binaries for new understandings and healing must be identified for culture care (Fujimura 2017). New materialist theory presents a break from dualistic thinking by applying a philosophy of immanence (Atkinson 2017; Braidotti 2019; Tuin and Dolphijn 2012) to focus what we are becoming together since "we-are-all-in-this-together-but-we-are-not-one-and-the-same" (Braidotti 2019, p. 157).

In order to emphasize the transition from dualistic thinking towards a new materialist framework, the terms of mercy, grace, and hope were intentionally selected to address the binary narratives of conservative-liberal, evangelical-secular, and republican-democrat in America. Despite which perspective one may ascribe to, the concepts of mercy, grace, and hope generally have a positive reception to counter hate and violence. These terms were then diffractively read through their reflective secular and theological understandings in order to develop a new materialist understanding of what mercy, grace, and hope means within a philosophy of immanence. Introducing this approach to mercy, grace, and hope within a new materialist framework that is material-discursive provides a way for exploring how experiences with art can produce differences in the world (Atkinson 2017).

Artworks were then explored within this framework to detail how mercy, grace, and hope could begin to understand the relational differences in the worlds becoming emerging from intra-acting with art. Since agency is not a human or nonhuman trait, the artwork is not acting out mercy, grace, or hope since that would be reflective and representationalist thought (Barad 2007). Instead, agency is the relation between matter that forms an agential cut, meaning a difference of mercy, grace, and hope can emerge in the world. Again, the artwork does not enact or bestow mercy, grace, or hope. Rather, through experiencing an artwork, a merciful, graceful, or hopeful difference can form in the world's becoming. An investigation of Becoming Us by Megan Constance Altieri and the Teeter-Totter Wall by Ronald Rael further details the argument for a new materialist understanding of art as stewardship. This approach to art has the potentiality to resist dualistic thinking and transcend present culture war divisions to present a mutual ethical appreciation for the arts to influence the world's becoming.

What new questions can be asked and new potentialities emerge when multiple perspectives of research sincerely engage with the force of art to express mercy, grace, and hope as stewardship? While this article proposes new materialist understandings for mercy, grace, and hope and investigates multiple artworks, further work and discussions must take place regarding the shared endeavor of the world's continuous becoming, within which art is entangled. If the arts are to be understood as a significant force for cultural and environmental stewardship during polarized times, then rigorous cross-disciplinary discussions must occur to lower divisions and present a collective approach through a new materialist framework for exploring the entangled force of art.

Funding: This research received no external funding.

Acknowledgments: As an entangled being who is embodied and embedded in this world, I recognize that I currently have a particular voice as a result of my becoming. Furthermore, my relations to various readings, artworks, people, and places all speak through this writing. Consequently, my voice is an entanglement of what I wish to say along with the sequencing of what others have said through their words' continuous becoming. While I am unable to acknowledge all these contributing factors, I would like to thank Cheryl, Chris Friese, otandka, Ouahidb, and Ted for sharing their content online through Creative Commons licensing, promoting the open access spread of content. I want to give a special thank you to Megan Altieri and Ronal Rael for their gracious support by providing images and publication permissions of their artworks. I would also like to thank Gail Jacky for her writing guidance and the Northern Illinois University Art and Design Education faculty and doctoral 
student cohort for sharing their passion and knowledge for the arts. Finally, I would like to thank my amazing wife Chelsey Leonard for her continuous compassion and support.

Conflicts of Interest: The author declares no conflict of interest.

\section{References}

Acuff, Joni Boyd. 2020. Afrofuturism: Reimagining Art Curricula for Black Existence. Art Education 73: 13-21. [CrossRef]

Atkinson, Dennis. 2017. Art, Disobedience, and Ethics: The Adventure of Pedagogy. Berlin \Heidelberg: Springer.

Aulich, Jim, and Mary Ikoniadou. 2020. Ghost stories for grown-ups: Pictorial Matters in Times of War and Conflict. Humanities 9: 44. [CrossRef]

Baker's Evangelical Dictionary of Biblical Theology. 1897a. s.v. "Mercy". Available online: https://www. biblestudytools.com/dictionary/mercy/ (accessed on 28 May 2020).

Baker's Evangelical Dictionary of Biblical Theology. 1987b. s.v. "Grace". Available online: https://www. biblestudytools.com/dictionary/grace (accessed on 28 May 2020).

Baker's Evangelical Dictionary of Biblical Theology. 1897c. s.v. "Hope". Available online: https://www. biblestudytools.com/dictionary/hope/ (accessed on 28 May 2020).

Barad, K. 2003. Posthumanist performativity: Toward an understanding of how matter comes to matter. Signs: Journal of women in culture and society 28: 801-831. [CrossRef]

Barad, Karen. 2007. Meeting the Universe Halfway: Quantum Physics and the Entanglement of Matter and Meaning. Durham: Duke University Press.

Barajas, Joshua. 2019. Why This Artist Used Seesaws to Protest at the Border. PBS. August 16. Available online: https://www.pbs.org/newshour/arts/pink-seesaws-at-the-border-wall-showed-that-play-is-a-formof-protest (accessed on 2 June 2020).

Blandy, Doug, and Paul E. Bolin. 2018. Learning Things: Material Culture in Art Education. New York: Teachers College Press.

Bolin, Paul E., and Doug Blandy. 2003. Beyond visual culture: Seven statements of support for material culture studies in art education. Studies in Art Education 44: 246-63. [CrossRef]

Braidotti, Rosi. 2019. Posthuman knowledge. Medford: Polity Press.

Brice, Anne. 2019. Teeter Totters as Activism: How the Border Wall Became a Playground. Berkeley News. October 8. Available online: https://news.berkeley.edu/2019/10/08/teeter-totters-as-activism-ronald-rael/ (accessed on 2 June 2020).

Butler, Judith. 2020. The Force of Non-Violence. Brooklyn: Verso.

Cameron, Fiona. 2018. Posthuman Museum Practices. In Posthuman Glossary. Edited by Rosi Braidotti and Maria Hlavajova. London: Bloomsbury Publishing, pp. 349-52.

Coulthard, Glen Sean. 2014. Red Skin, White Masks: Rejecting the Colonial Politics of Recognition. Minneapolis: U of Minnesota Press.

Coulthard, Glen, and Leanne Betasamosake Simpson. 2016. Grounded normativity/place-based solidarity. American Quarterly 68: 249-55. [CrossRef]

Csikszentmihalyi, Mihaly. 1996. Creativity the Psychology of Discovery and Invention. New York: HarperCollins Publishers.

Davies, Paul. 2020. Physics and the Mind of God: The Templeton Prize Address. First Things. Available online: https://www.firstthings.com/article/1995/08/003-physics-and-the-mind-of-god-the-templeton-prizeaddress-24 (accessed on 2 June 2020).

de Freitas, Elizabeth, and Matthew X. Curinga. 2015. New materialist approaches to the study of language and identity: Assembling the posthuman subject. Curriculum Inquiry 45: 249-65. [CrossRef]

De Line, Sebastian. 2016. All my/our relations: Can posthumanism be decolonized. Open! Platform for Art, Culture the Public Domain, July 7.

Deleuze, Gilles, and Félix Guattari. 2005. A Thousand Plateaus: Capitalism and Schizophrenia, 11th ed. Minneapolis: University of Minnesota Press. First published 1980.

Deloria, Vine. 1988. Custer Died for Your Sins: An Indian Manifesto. Norman: University of Oklahoma Press.

Deloria, Vine. 1999a. For This Land: Writings on Religion in America. New York: Routledge.

Deloria, Vine. 1999b. Spirit E Reason: The Vine Deloria, Jr., Reader. Golden: Fulcrum Publishing. 
Dery, Mark. 1994. Black to the Future: Interviews with Samuel R. Delany, Greg Tate, and Tricia Rose. Flame Wars: The Discourse of Cyberculture, 179-222.

Desliver, Drew, Michael Lipka, and Dalia Fahmy. 2020. 10 Things We Know about Race and Policing in the U.S. Pew Research Center. Available online: https:/www.pewresearch.org/fact-tank/2020/06/03/10-things-weknow-about-race-and-policing-in-the-u-s/ (accessed on 3 June 2020).

Dewey, John. 2008. The Later Works, 1925-1953 John Dewey. Vol. 1, Edited by Jo Ann Boydston. Carbondale: Southern Illinois University Press, p. 4. First published 1984.

Eshun, Kodwo. 2003. Further considerations of Afrofuturism. CR: The New Centennial Review 3: $287-302$. [CrossRef]

Fujimura, Makoto. 2012. Visual Theology. Makoto Fujimura. April 10. Available online: https://www. makotofujimura.com/writings/visual-theology/ (accessed on 2 June 2020).

Fujimura, Makoto. 2017. Culture Care: Reconnecting with Beauty for Our Common Life. Downers Grove: InterVarsity Press.

Gallagher, Paul. 2017. Wear with Confidence: Nick Cave's Beautiful and Empowering Soundsuits. Dangerous Minds. February 6. Available online: https://dangerousminds.net/comments/wear_with_confidence_nick_ caves_beautiful_empowering_soundsuits (accessed on 16 July 2020).

Garber, Elizabeth. 2019. Objects and New Materialisms: A Journey across Making and Living With Objects. Studies in Art Education 60: 7-21. [CrossRef]

Greene, Maxine. 1995. Releasing the Imagination: Essays on Education, the Arts, and Social Change. San Francisco: Jossey-Bass.

Guo, Wen. 2017. The Celebration of Ghosts: A Postmodern Theoretical Framework of Meaning-Making in Visual Art Education. Studies in Art Education 58: 184-94. [CrossRef]

Hagemann, Hannah. 2020. George Floyd Reverberates Globally: Thousands Protest in Germany, U.K., New Zealand. May 31. Available online: https://www.npr.org/2020/05/31/866428272/george-floyd-reverberatesglobally-thousands-protest-in-germany-u-k-canada (accessed on 1 June 2020).

Haraway, Donna. 1994. A manifesto for cyborgs: Science, technology, and socialist feminism in the 1980s. In The Postmodern Turn: New Perspectives on Social Theory. Edited by Steven Seldman. Cambridge: Cambridge University Press, pp. 82-115.

Haraway, Donna. 2006. A cyborg manifesto: Science, technology, and socialist-feminism in the late 20th century. In The International Handbook of Virtual Learning Environments. Edited by Joel Weiss, Jeremy Hunsinger and Peter Trifonas. Dordrecht: Springer, pp. 117-58.

Haraway, Donna. 2013. Simians, Cyborgs, and Women: The Reinvention of Nature. London: Routledge.

Haraway, Donna J. 2016. Staying with the Trouble: Making Kin in the Chthulucene. Durham: Duke University Press. Harris, Sam. 2020. Science can Answer Moral Questions. Filmed 2010, TED Video. Available online: https: //ed.ted.com/lessons/science-can-answer-moral-questions-sam-harris (accessed on 2 June 2020).

Harris, Sam. 2011. The Moral Landscape: How Science can Determine Human Values. New York: Simon and Schuster.

Hayles, N. Katherine. 2008. How we Became Posthuman: Virtual Bodies in Cybernetics, Literature, and Informatics. Chicago: University of Chicago Press.

Hayles, N. Katherine. 2017. Unthought: The Power of the Cognitive Nonconscious. Chicago: University of Chicago Press.

Heardman, Adam. 2019. I Believe Artists Work More Than Anyone: 'Calligraffiti' Artist EL Seed on How Art Can Change Global Perspectives. Mural Art. April 17. Available online: https://www.mutualart.com/Article/IBelieve-Artists-Work-More-Than-Anyone-/B76AFD237F4F9848 (accessed on 2 June 2020).

Higgins, Marc. 2017. Post-qualitative mo(ve)ments: Concluding remarks on methodological response-abilities and being wounded by thought. Reconceptualizing Educational Research Methodology 8: 89-101. [CrossRef]

Hume, David. 2003. A Treatise of Human Nature. Mineola: Dover Publications.

Hunter, James Davison, and Paul Nedelisky. 2018. Science and the Good: The Tragic Quest for the Foundations of Morality. London: Yale University Press.

Kaplan, Heather. 2019. Border Materials, Early Childhood Art Education, and the Ontological Persistence of American Flexibility. Studies in Art Education 60: 120-31. [CrossRef]

Keifer-Boyd, Karen. 2018. (re) Vision Visual Culture. Studies in Art Education 59: 174-78. [CrossRef]

Kleinherenbrink, Arjen. 2015. Territory and ritornello: Deleuze and Guattari on thinking living beings. Deleuze Studies 9: 208-30. [CrossRef] 
le Grange, Lesley. 2018. The notion of Ubuntu and the (post) humanist condition. In Indigenous Philosophies of Education around the World. Edited by John Petrovic and Roxanne Mitchell. New York: Routledge, pp. 40-60.

Leonard, Nicholas. 2020. Entanglement Art Education: Factoring In ARTificial Intelligence and Nonhumans into Future Art Curricula. Art Education 73: 22-28. [CrossRef]

Love, Bettina L. 2019. We Want to Do More Than Survive: Abolitionist Teaching and the Pursuit of Educational Freedom. Boston: Beacon Press.

Martin, Brian. 2017. Methodology is content: Indigenous approaches to research and knowledge. Educational Philosophy and Theory 49: 1392-400. [CrossRef]

Mayer, Ruth. 2000. Africa As an Alien Future: The Middle Passage, Afrofuturism, and Postcolonial Waterworlds. Amerikastudien/American Studies 45: 555-66.

Megan Constance Altieri. 2020. Becoming Us. Available online: https://www.meganconstancealtieri.com/ becoming-us (accessed on 2 June 2020).

Morris, Susana M. 2012. Black Girls Are from the Future: Afrofuturist Feminism in Octavia E. Butler's "Fledgling". Women's Studies Quarterly 40: 146-66. [CrossRef]

Nakata, Martin N. 2007. Disciplining the Savages, Savaging the Disciplines. Canberra: Aboriginal Studies Press.

Nelson, Alondra. 2000. Afrofuturism: Past-Future Visions. Color Lines 3: 34-47.

Pew Research Center. 2020. White Evangelicals See Trump as Fighting for Their Beliefs, Though Many Have Mixed Feelings about His Personal Conduct. Published on 12 March 2020. Available online: https://www.pewforum.org/2020/03/12/white-evangelicals-see-trump-as-fighting-for-theirbeliefs-though-many-have-mixed-feelings-about-his-personal-conduct/ (accessed on 2 June 2020).

Polanyi, Michael. 1967. The Tacit Dimension. New York: Anchor Books.

Polkinghorne, John Charlton. 2005. Exploring Reality: The Intertwining of Science and Religion. London: Yale University Press.

Polkinghorne, John Charlton. 2007. Quantum Physics and Theology: An Unexpected Kinship. London: Yale University Press.

Polkinghorne, John. 2010. The Polkinghorne Reader: Science, Faith and the Search for Meaning. Edited by Thomas Jay Oord. West Conshohocken: Templeton Press.

Polkinghorne, John Charlton, and John Levett. 1994. Quarks, Chaos, and Christianity: Questions to Science and Religion. New York: Crossroad.

Rael, Ronald. 2017. Borderwall as architecture: A manifesto for the U.S.-Mexico Boundary. In Borders, Fences and Walls: State of Insecurity? Berkeley: University of California Press.

Rech Penn, Leslie. 2019. Drawing, Bodies, and Difference: Heterocorporeal Dialogs and Other Intra-Actions in Children's Classroom Drawing. Studies in Art Education 60: 103-19. [CrossRef]

Rosiek, J.L., J. Snyder, and S.L. Pratt. 2020. The new materialisms and Indigenous theories of non-human agency: Making the case for respectful anti-colonial engagement. Qualitative Inquiry 26: 331-46. [CrossRef]

Schaeffer, Katherine. 2020. Far More Americans See 'Very Strong' Partisan Conflicts Now than in the Last Two Presidential Election Years. Pew Research Center. March 4. Available online: https://www.pewresearch.org/fact-tank/2020/03/04/far-more-americans-see-very-strong-partisanconflicts-now-than-in-the-last-two-presidential-election-years/ (accessed on 2 June 2020).

Schulte, Christopher M. 2019. Wild Encounters: A More-Than-Human Approach to Children's Drawing. Studies in Art Education 60: 92-102. [CrossRef]

Seed, L. 2020. Cairo Perception. Available online: https:/elseed-art.com/projects/perception-cairo/ (accessed on 4 June 2020).

Sherman, Aleksandra, and Clair Morrissey. 2017. What is art good for? the socio-epistemic value of art. Frontiers in Human Neuroscience 11: 411. [CrossRef] [PubMed]

Siegesmund, Richard, and Kerry Freedman. 2018. Interpreting visual information in research: Tacit knowledge and nomadic inquiry. ECQI 2018 PROCEEDINGS (2018), 34-40.

Simpson, Leanne Betasamosake. 2017. As We Have Always Done: Indigenous Freedom through Radical Resistance. Minneapolis: University of Minnesota Press.

Spinoza, Baruch. 1996. Ethics. London: Penguin.

Sullivan, Graeme. 2006. Research acts in art practice. Studies in art Education 48: 19-35. [CrossRef]

Taimina, Daina. 2018. Crocheting Adventures with Hyperbolic Planes: Tactile Mathematics, Art and Craft for All to Explore. Boca Raton: CRC Press. 
Todd, Zoe. 2014. Fish pluralities: Human-animal relations and sites of engagement in Paulatuuq, Arctic Canada. Études/Inuit/Studies 38: 217-38. [CrossRef]

Todd, Zoe. 2016. An indigenous feminist's take on the ontological “Ontology" is just another word for colonialism. Journal of Historical Sociology 29: 4-22. [CrossRef]

Tuck, Eve, and Marcia McKenzie. 2015. Place in Research: Theory, Methodology, and Methods. New York: Routledge.

Tuin, Iris van der, and Rick Dolphijn. 2012. New Materialism: Interviews \& Cartographies. London: Open Humanities Press.

University of Glasgow. 2018. The Glasgow Gifford Lectures: Judith Butler (1 October 2018). 8 October 2018. Video, 1:35.16. Available online: https://www.youtube.com/watch?time_continue=954\&v=3sczWpL0y-w\&feature= emb_title (accessed on 2 June 2020).

Van Huyssteen, J. Wentzel. 2006. Alone in the World? Human Uniqueness in Science and Theology. Grand Rapids: William B. Eerdmans Publishing Company.

Watts, Vanessa. 2013. Indigenous place-thought and agency amongst humans and non humans (First Woman and Sky Woman go on a European world tour!). Decolonization: Indigeneity, Education E Society 2: 20-34.

Wertheim, Margaret. 2009. The Beautiful Math of Coral. Filmed 2009, TED Video. Available online: https: //www.ted.com/talks/margaret_wertheim_the_beautiful_math_of_coral\#t-701337 (accessed on 4 June 2020).

Wertheim, Margaret. 2020. Science Art Project: Crochet Coral Reef. Margaret Wertheim. Available online: https://www.margaretwertheim.com/crochet-coral-reef (accessed on 3 June 2020).

Whithead, Alfred North. 1978. Process and Reality. New York: Free Press.

Wiebe, David. 2019. A Materialist Response to Hunter and Nedelisky's Science and the Good. Journal of Sociology and Christianity 9: 99-104.

Yaszek, Lisa. 2006. Afrofuturism, science fiction, and the history of the future. Socialism and Democracy 20: 41-60. [CrossRef]

Ziarek, Krzysztof. 2004. The Force of Art. Palo Alto: Stanford University Press.

(C) 2020 by the author. Licensee MDPI, Basel, Switzerland. This article is an open access article distributed under the terms and conditions of the Creative Commons Attribution (CC BY) license (http://creativecommons.org/licenses/by/4.0/). 